\title{
Performance Evaluation of a Novel Sampling and Measurement System for Exhaust Particle Characterization
}

\author{
Leonidas Ntziachristos, Barouch Giechaskiel, Panayotis Pistikopoulos and Zissis Samaras \\ Laboratory of Applied Thermodynamics / Aristotle University Thessaloniki
}

Urs Mathis and Martin Mohr

Swiss Federal Laboratories for Materials Testing and Research (EMPA)

Jyrki Ristimäki and Jorma Keskinen

Tampere University of Technology / Institute of Physics / Aerosol Physics Laboratory

Pirita Mikkanen

Dekati Ltd

Roberto Casati, Volker Scheer and Rainer Vogt

Ford Forschungszentrum Aachen

Copyright $\odot 2004$ SAE International

\begin{abstract}
This paper presents a novel partial flow sampling system for the characterization of airborne exhaust particle emissions. The sampled aerosol is first conditioned in a porous dilutor and then subsequent ejector dilutors are used to decrease its concentration to the range of the instrumentation used. First we examine the sensitivity of aerosol properties to boundary sampling conditions. This information is then used to select suitable sampling parameters to distinguish both the nucleation and the accumulation mode. Selecting appropriate sampling parameters, it is demonstrated that a distinct nucleation mode can be formed and measured with different instruments. Using these parameters we examine the performance of the system over transient vehicle operation. Additionally, we performed calculations of particle losses in the various components of the system which are then used to correct signals from the instruments. Several quality characteristics are then discussed, such as the repeatability and reproducibility of the measurements and the potential to derive total emission rate with a partial flow sampling system. Comparisons in different laboratories show that repeatability (intra-laboratory variability) is in the order of $10 \%$ for accumulation mode particles and $50 \%$ for nucleation mode ones. Reproducibility (inter-laboratory variability) values are in the range of $\pm 20-30 \%$. Finally, we compared laboratory size distributions with ambient samples obtained chasing a vehicle. This demonstrated that the sampling system accurately reproduced the accumulation mode particles as well as the potential for nucleation mode formation. This sampling system has
\end{abstract}

been used in the framework of a European project for measurement of emissions of a number of light duty vehicles and heavy duty engines.

\section{INTRODUCTION}

Exhaust particle sampling and conditioning has become a major issue over the last years as the characterization of exhaust particles becomes more and more sophisticated. There are two main reasons that led to the need for a detailed characterization of exhaust aerosol. Firstly, more information on the properties of the emitted particles is necessary to understand their origin and formation in order to more effectively regulate their exhaust concentration. Secondly, studies of particle health effects request more particle dimensions to better associate observations with emissions. In this respect, almost all recent investigations on particulate matter (PM) emissions of vehicles customarily report in addition to mass, at least number concentrations and number weighted size distributions. However, it has been a common place for years that number concentration is very sensitive to sampling conditions and one can report various results, depending on the sampling parameters used in a particular study $[1,2]$. This has partially shifted the interest from the measurement result as such to the conditioning (aging) procedure selected for the specific measurement.

The European Research project "PARTICULATES", funded by the European Commission - Directorate General Energy and Transport (EC-DG TREN), aimed at the exhaust particle characterization of a number of light 
duty vehicles and heavy duty engines. The main focus was to develop a database where emission factors of a number of particle properties could be derived, on the basis of measurements conducted at various laboratories across Europe, covering a large range of vehicle/engine operating conditions. It is evident that in a project like this, selection of the sampling conditions was of high priority and importance, if one wished to obtain at least comparable results between different laboratories. Otherwise it would be highly questionable if results obtained following different sampling protocols could be collected and compared in a common database. Therefore, we developed a partial flow sampling system (PFSS) to provide the same sampling conditions in all measuring laboratories. Using a PFSS, conditioning of the exhaust aerosol can be performed in the same manner regardless of the physical environment where the measurement is conducted (laboratory) and the type of exhaust aerosol source (diesel engine, spark ignition vehicle, etc.).

This paper provides the details of the sampling system developed and its operational characteristics. At first we present the shortcomings of CVS-type of installations for exhaust aerosol characterization to justify the need for a PFSS development. Then the PFSS development and the selection of the sampling conditions are described. A detailed analysis of the PFSS operation characteristics follows which examines its performance during transient vehicle operation. The PFSS is also validated with a comparison against the CVS, using solid diesel particles. We then demonstrate its capabilities for real-time characterization of exhaust aerosol using several case studies with different instruments. Finally, particle characteristics obtained with the PFSS are compared with exhaust samples obtained in chasing experiments in order to explore the relevance of our laboratory test procedure compared to "real-world" emissions.

\section{CONSTRAINTS OF THE CVS FOR EXHAUST PARTICLE CHARACTERIZATION}

Today's legislation in Europe and the US prescribe the CVS as the reference procedure for PM sampling both for heavy duty engines and light duty vehicles certification. Generally, there are no explicit specifications for the design of a full-flow CVS system apart from the need to maintain a constant flowrate and a temperature at PM collection location below $52^{\circ} \mathrm{C}$. Recently, the US 2007 regulation for heavy duty engine certification [3] required a stricter control of the temperature at the collection location in the range of $47 \pm 5^{\circ} \mathrm{C}$. This is associated with additional implications to dilution practices, such as control of the dilution air temperature, and no definite decisions on the practicalities of the new legislation have been taken yet.

There are clear advantages of the CVS procedure for certification tests. Dilution of the exhaust reduces the risk of water condensation in the sampling and transport lines. Stabilization of the exhaust reduces pressure and temperature fluctuations, thus simplifying the sampling procedure. The constant flowrate established is precisely controlled and measured. Therefore, samples of PM and gaseous pollutants can be easily reduced to the vehicle exhaust even over transient cycles, by just correcting for the background dilution air concentration.

However, several exhaust conditioning parameters are left uncontrolled in the CVS. Primarily, the dilution ratio (DR), that is the ratio of diluted over raw exhaust, has been left out of a direct regulation and is only implicitly controlled by the need to achieve sufficient exhaust cooling before PM sampling. Together with temperature, DR has a profound effect on the collected particulate quantity because it affects the behavior of condensable species (organic material, sulfates and water). This has been already shown in several pioneering papers $[4,5]$ where an isothermal increase of the DR was found to reduce the collected $P M$ due to the smaller relative contribution of the volatile fraction (VF). A more recent investigation [6] demonstrated that increase of DR from $7: 1$ to $29: 1$ with a subsequent filter face temperature shift from $45^{\circ} \mathrm{C}$ to $33^{\circ} \mathrm{C}$ increased $\mathrm{PM}$ by $25 \%$ over a moderate speed/load condition. However, both conditions are well within the limits of the regulations. In this respect, the level of PM determined with the CVS has started to be considered as a function of the DR selected [7]. Such effects are responsible for the up to $20 \%$ difference in PM found in inter-laboratory comparisons, even when gaseous pollutants agree and outliers are excluded $[8,9]$.

The sensitivity of PM sampling on CVS conditioning parameters is only mentioned here to show that different full-flow sampling systems may still lead to deviations in the recorded $P M$, even if they fully comply with regulatory requirements. Such an effect is significantly amplified when number concentration and size distribution of particles are of concern. Using specialized sampling equipment, Kittelson and co-workers $[1,10]$ showed that one can in principle obtain any distribution for the nucleation mode particles, by just modifying the conditioning parameters within the range permitted by the reference method for PM sampling. They actually identified that DR, temperature and residence time (RT) of the exhaust gas at diluted conditions have an important effect on the size distributions obtained. This was achieved using dilutors specifically designed to provide a defined sampling environment and it should be expected that similar effects should be somehow averaged in an unmodified CVS. Still, significant effects of the CVS sampling conditions should be expected especially when new exhaust systems equipped with diesel particle filters need to be studied. The lack of a solid accumulation mode in such cases may lead to unexpected growth of the nucleation mode even with moderate DR variance [11]. Finally, DR determination uncertainties may provide a secondary source of measurement variability, even in cases where no particular shift of the nucleation mode takes place [12]

The variability induced by the conditioning parameters in the aerosol characteristics has two significant implications when the emission performance of different 
engines in different labs is concerned. At first, the same engine might produce significantly different results when tested in CVS systems operating at different flowrates, and subsequently DR, temperature and RT. This would significantly affect the reproducibility of the measurements. Even when testing a particular engine on a single laboratory, the conditioning of exhaust changes as operating modes vary. While RT in the dilution tunnel remains practically the same for different modes, both DR and temperature change significantly. Hence, distinction of emission effects to primary (engine) and secondary (conditioning) ones would be impossible.

There are additional constraints in the application of the CVS procedure. In particular, the design and condition of the transfer line from the exhaust pipe to the dilution tunnel inlet is a significant source of artifacts $[13,14]$. Such artifacts originate from the transient thermal condition. Although not straightforward in perception, they are probably more prominent in steady-state tests rather than transient cycles. They mainly appear during step increase functions of exhaust temperature which may lead to subsequent release of volatile material from the transfer line walls. And while one may design a new CVS system to avoid such artifacts, this is not possible in existing dilution systems available in different labs.

\section{SAMPLING SYSTEM DESIGN CRITERIA}

In order to address these concerns and to allow preferential conditioning of aerosol samples, we designed a PFSS which draws exhaust directly from the tailpipe. PFSSs have been developing for years mainly to reduce the cost and space required for a full CVS installation. Vouitsis et al. [15] provide a summary of the principles governing different sampling systems focusing on type-approval measurements. In such systems it is critical to maintain a constant split ratio with the exhaust gas flowrate, i.e. the fraction of exhaust gas drawn in the sampling system should always be proportional of the total exhaust gas flowrate, even during a transient cycle. This is required in order that the integral of the product of mass concentration and exhaust gas flowrate over a transient test is proportional to PM collected on a CVS. Such systems make use of electronic sensors and fast response pneumatic controls to maintain the proportionality [8]

Our intention was not to develop a system for use in certification tests. Hence, maintaining equivalence with the reference procedure for mass measurements and flow proportionality were not an issue. Rather, our target has been to achieve sampling of the exhaust gas using constant and repeatable conditioning parameters (DR, RT, temperature and humidity) even over a transient test. Furthermore, sampling conditions should be independent of engine size and operation mode and should be identical in different environments (laboratories). This can be realized by drawing a portion of exhaust gas at a constant flowrate and diluting it with air at constant dilution ratio, air temperature and air humidity. Using such a "constant flowrate" PFSS, control of the conditioning parameters can be realized at relatively limited cost.

Sampling conditions in such a system should in principle be selected to mimic atmospheric mixing and dilution. However, this process is practically impossible to precisely reproduce in the lab, because of its complexity and its dependence on the (variable) ambient conditions. instead, the selection of conditions which should allow repeatable formation of the nucleation mode in the lab was set as a target. This would allow the identification of cases (engine operating modes, fuels, etc.) where there is a potential for nucleation mode formation.

Finally, the sampling system should enable the measurement of a broad range of particle properties over transient tests. In particular, size, number concentration and surface of particles have been considered important. Additionally, separation of solid soot particles from volatile ones was deemed necessary.

\section{SYSTEM DESCRIPTION}

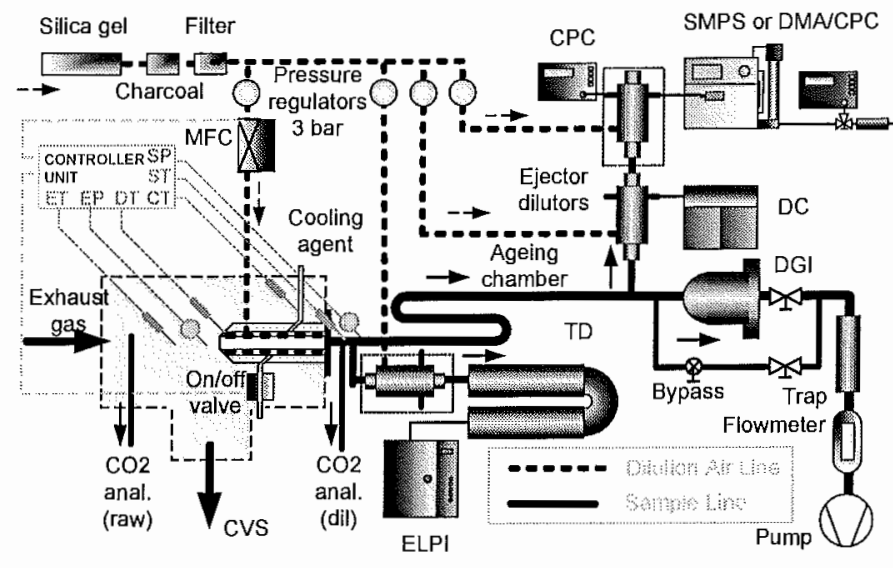

Figure 1: A typical configuration of the sampling system used in this study. Exhaust gas is drawn with a porous dilutor and then split to two branches: in the "dry" branch a TD strips condensable material and solid particles are sampled with an ELPI. In the "wet" branch particles are aged in an aging chamber and subsequently sampled with a DC, a CPC/SMPS and a DGI. Signals recorded for primary dilution control include the exhaust gas temperature (ET) and pressure (EP), the dilution air temperature at the tip of the probe (DAT) and the diluted sample temperature (ST) and pressure (SP). Raw and diluted $\mathrm{CO}_{2}$ concentrations are used for DR determination.

The typical setup of the PARTICULATES sampling system can be seen in Figure 1. A small portion of the exhaust gas enters the primary dilutor (porous dilutor) and is diluted with dehumidified (humidity $<5 \%$ ) and filtered air at quasi-constant temperature which depends on the sampling conditions selected. The diluted exhaust gas stream is further divided into 2 branches, called "wet" and "dry" ones by convention. In the heater of the dry branch the diluted sample is heated up to $250^{\circ} \mathrm{C}$ to evaporate all volatile material which is subsequently adsorbed in the denuder. The volatile-free 
sample is then fed to the ELPI to provide the solid particle number concentration and size distribution. Optionally, a secondary ejector dilutor can be used upstream of the thermodenuder (TD) to decrease the volatiles concentration and extent the TD lifetime. In the wet branch the sample passes through an ageing chamber which provides time for nucleation mode growth. The largest fraction of the diluted exhaust enters a cascade impactor (Dekati Gravimetric Impactor - DGI) which provides the mass-weighted size distribution of the exhaust aerosol. A small quantity is further diluted with ejector dilutors and is sampled with a diffusion charger (DC) which provides the active particle surface and a Condensation Particle Counter (CPC) which provides the number concentration. Over steady state tests a Scanning Mobility Particle Sizer (SMPS) replaces the CPC to additionally provide the number-weighted size distribution of the sample particles.

\section{PRIMARY DILUTION}

The details of the primary porous dilutor have already been presented by Mikkanen et al. [16]. A small portion of the exhaust gas $(5-10 \mathrm{l} / \mathrm{min}$, i.e. less than $1 \%$ for a typical passenger car exhaust gas flowrate of $60 \mathrm{~m}^{3} / \mathrm{h}$ ) is drawn by the porous dilutor, which is located directly in the exit of the tailpipe. With the porous dilutor no isokinetic sampling is achieved but this is not important for particles smaller than $1 \mu \mathrm{m}$. The theoretical aspiration efficiency of the porous dilutor is given in [16]. Additionally, it should be reminded that the system presented here is not intended for PM sampling, hence anisokinetic errors such as the ones presented by Silvis et al. [8] are even less relevant.

In the porous dilutor the dilution air is mostly introduced at the tip of the sampling probe. A smaller fraction of dilution air is progressively added downstream in the diluted sample through the periphery of the perforated (porous) tube to minimize particle losses on the walls. The flowrate of the dilution air is controlled by a mass flow controller and is set to a constant value throughout the measurement, depending on the required DR. The $\mathrm{RT}$ in the porous dilutor is in the order of a couple of milliseconds, depending on the flowrate set. This fast primary dilution increases supersaturation ratios of semi volatile species and hence is expected to enhance the potential for nucleation.

The flowrate of the diluted sample equals the sum of flowrates downstream of the primary dilutor. Hence the flowrate of exhaust sample could in principle be derived as the difference of two quantities (dilution air and diluted sample) and the DR could be calculated. In reality there are several problems in such an approach. First, the sample flowrate should be deduced as the difference of two much larger quantities which is problematic as such. Secondly and most importantly, pressure fluctuations in the tailpipe may force a fraction of the dilution air to be exhausted in the tailpipe rather than in the porous dilutor (backflow). Therefore, it was decided that raw and diluted $\mathrm{CO}_{2}$ concentrations should be used for determination of the $\mathrm{DR}$, rather than flowrates.

Further to DR and RT, dilution air temperature (DAT) is the third parameter to be controlled. The target is to achieve mixing with constant temperature dilution air even during transients, to simulate ambient dilution process. The cooling of the primary dilutor is achieved with coolant flow in an external jacket. Water or air can be used for cooling and their flowrate is adjusted with a solenoid controlled by DAT. Due to the thermal inertia of the system and the dilution of the exhaust gas, flowrate control does not need to be too precise or responsive. As DAT can be externally adjusted to a large range, hot dilution tests can also be performed.

Dilution air relative humidity $(\mathrm{RH})$ may be an additional variable in the mixing process. Measurements conducted by Abdul-Khalek et al. [1] showed that an increase of the sample $\mathrm{RH}$ from $15 \%$ to $40 \%$ increased nanoparticle concentration by $30 \%$. However, even when sample $\mathrm{RH}$ reaches values as low as $2 \%$, the nucleation mode is still preserved. It was therefore decided that dry dilution air $(\mathrm{RH}<5 \%)$ should be used because this is a repeatable condition and technically easier to achieve. The dilution air is further purified by using an active charcoal filter for volatile material retention and a HEPA filter to remove background solid particles. Typically, FID measurements showed HC content less than 2 ppm (FID noise level) and CPCs measured background particle concentrations less than 5 particles $/ \mathrm{cm}^{3}$.

\section{DRY BRANCH}

As already mentioned above, this branch includes a TD and an ELPI and optionally an ejector dilutor. A Dekati high volume TD has been used to remove volatile and semivolatile compounds from sample aerosol particles at a heater setting at $250^{\circ} \mathrm{C}$ (residence time $\sim 0.3 \mathrm{~s}$ ). This temperature is generally considered sufficient for nucleation mode elimination [17, 18]. After heating, the volatile compounds are adsorbed onto active charcoal in the cooled adsorber section (denuder). Aerosol particles have slower diffusion velocities than the vaporized compounds and this results in a preferential retention of gaseous species than particles. A significant loss of particles also takes place mainly due to diffusion and thermodiffusion. Detailed data and discussion of the TD losses are provided at a section below.

ELPI is a widely known instrument in the area of exhaust aerosol measurements. In the present configuration it has been used to sample solid particles only, in order to avoid interference between the low pressure impaction stages and volatile nucleation mode particles.

\section{WET BRANCH}

Downstream of the primary dilutor, particles are led in the aging chamber where time is given for stabilization of the diluted sample. A large fraction is then led to a DGI which consists of 4 stages with $d_{50 \%}$ diameters at $2.5,1$, 
0.5 and $0.2 \mu \mathrm{m}$ (at nominal flowrate $70 \mathrm{l} / \mathrm{min}$ ). A $70 \mathrm{~mm}$ teflon-coated glass fiber filter is used downstream of the cascade impactor to collect smaller particles. DGI is not a real-time instrument. It can be used to record PM emission rate only over steady state tests, where the exhaust flowrate is constant. Over transients, it can only provide the cumulative mass size distribution which is not expected to be particularly dependant on exhaust flowrate, given the low instrument resolution. DGI was used to cross-check CVS PM and to collect particle samples for subsequent chemical analysis.

A smaller portion of the primarily diluted sample is further diluted with ejector dilutors to lower its concentration to levels appropriate for aerosol instrumentation. In an ejector type dilutor, exhaust sample flows through an inlet nozzle, due to the underpressure developed by dilution air flowing to a venturi formed in the periphery of the inlet nozzle. The dilution air is similarly conditioned to the one in the primary dilutor (but is at ambient temperature). The DR provided by the ejector dilutors depends on the upstream (sample) pressure, the pressure of the dilution air (for subsonic regulation of the dilution air) and the pressure where the diluted sample is discharged. Assuming sonic regulation for the dilution air and ambient conditions for discharge, DR depends only on the sample pressure. DR in ejector dilutors can be calibrated with $\mathrm{NO}$ in $\mathrm{N}_{2}$ as a function of sample pressure. Monitoring of the sample pressure during the measurement can then be used to correct the ejector DR. However the pressure at the first ejector inlet is always found in the range $990-1000 \mathrm{mbar}$, while the pressure in the second in series ejector dilutor is equal to ambient, hence the correction is negligible in both cases (see Figure 11 below). The residence time in each ejector dilutor is in the range of $0.3 \mathrm{~s}$.

Several properties of the exhaust aerosol are monitored in the wet branch. The CPC and SMPS are well established in this field and provide the number concentration in real time and the electrical mobility size distribution respectively. SMPS requires at least $90 \mathrm{~s}$ for a full scan in the range roughly $0.01-0.4 \mu \mathrm{m}$ (or 0.007 $0.3 \mu \mathrm{m}$ ), hence it can only be used over steady state conditions.

The DC is a less known instrument but has received much attention lately. In our DC, a corona discharge forms in the periphery of a thin wire at high voltage. The corona generates positive ions that diffuse onto aerosol particles and charge them. The combination of the charger with an aerosol electrometer results in an electrical aerosol detector that is capable of measuring particle concentrations. According to Siegmann and Siegmann [19], a DC records the particle "active" surface. The precise definition of active surface is rather equivocal and in strict terms it represents the surface area of particles in the free-molecular regime which is available for ion diffusion. In practical application, the "active" surface is a handy expression of particle surface area which can be obtained in real-time and is sensitive enough to be correlated with the CPC concentration to provide mean particle size in real-time [20]. In the particular instrument used in this study (Dekati prototype), all particles with aerodynamic diameter $>1 \mu \mathrm{m}$ are separated by an impactor, to avoid interference with smaller particles. Particles $<1 \mu \mathrm{m}$ are collected on a filter stage and produce an electrical current, which is recorded in real time. This instrument has been calibrated with diesel monodisperse and polydisperse aerosol [21].

\section{SAMPLING CONDITIONS}

\section{SELECTION OF DR, DAT, RT}

One of the main decisions of the project consortium was to develop sampling conditions which would enhance nucleation mode formation. This information would be compared with measurements of solid particles obtained in the dry branch to separately observe effects on solid and total particle populations. In order to maximize the potential for nucleation mode formation, one would preferably choose a low DR not to substantially decrease the concentration of volatile species and a low DAT to increase the saturation ratios. However, practical difficulties (cooling, sampling) limit the range of DR-DAT range that can be reliably and repeatedly achieved in the laboratory.

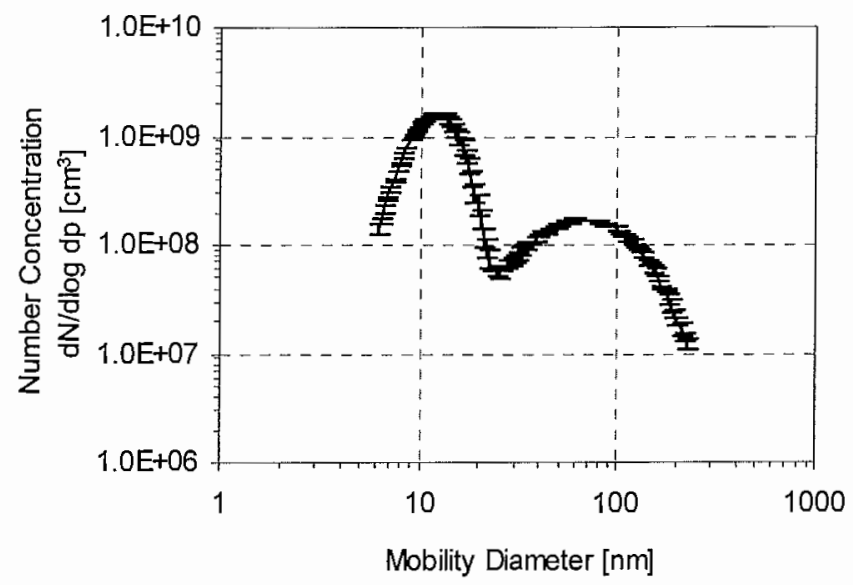

Figure 2: Typical size distribution of a Skoda Octavia TDI (Euro 2) measured at $50 \mathrm{~km} / \mathrm{h}, 7 \mathrm{~kW}$ load. A clear distinction between nucleation mode and accumulation mode is observed (Sampling conditions: DR: $17: 1$, DAT: $\left.20^{\circ} \mathrm{C}, \mathrm{RT}: 3.1 \mathrm{~s}\right)$.

An additional constraint in the selection of sampling parameters is that the formation of nucleation mode should not be too sensitive to sampling conditions. Otherwise, small deviations of DR or DAT might induce a large variability to nucleation mode, affecting the measurement repeatability. This tendency can only be investigated experimentally, due to the absence of a mature theoretical approach. We used a Euro 2 Skoda Octavia TDI 1.9 I car, to investigate this sensitivity. A few preliminary SMPS scans showed that a distinct 
nucleation mode can be formed at $50 \mathrm{~km} / \mathrm{h}$ under moderate load conditions (Figure 2) and this driving condition was selected for experimentations with different DR-DAT combinations.

Figure 3 shows the sensitivity of the nucleation mode particles to incremental differences of the $D R( \pm 1$ unit) and DAT $\left( \pm 0.5^{\circ} \mathrm{C}\right)$. Figure 3 data are based on measurements performed with an SMPS over multiple tests with various sampling conditions. In each of those tests nucleation mode particles were somewhat arbitrarily defined as those with sizes $<0.026 \mu \mathrm{m}$ and thus discriminated from accumulation mode particles. The figure shows that in principle, no nucleation mode was visible above $40^{\circ} \mathrm{C}$ for any DR examined. However, at lower temperatures, number concentration of nanoparticles is sensitive to sampling conditions which is an evidence of nucleation mode formation. In order to obtain both small sensitivity to sampling conditions and nucleation mode formation, two ranges can be identified in this chart, one at DR $\sim 12: 1$ and $\mathrm{DAT} \sim 30^{\circ} \mathrm{C}$ and one at DR 20:1 and DAT $20^{\circ} \mathrm{C}$. It was decided to select the lower DR and higher DAT sampling "window" because it is easier to reach with cooling in ambient temperature and does not require high dilution, which is preferential in a porous dilutor to eliminate backflow effects. Obviously, results have been obtained only on one vehicle and one driving condition. Therefore, it cannot be excluded that a different picture would be taken for a different vehicle and/or driving condition. Although this is a valid assumption, results obtained in the course of the project on different occasions seem to confirm a repeatable reproduction of nucleation for the selected conditions.

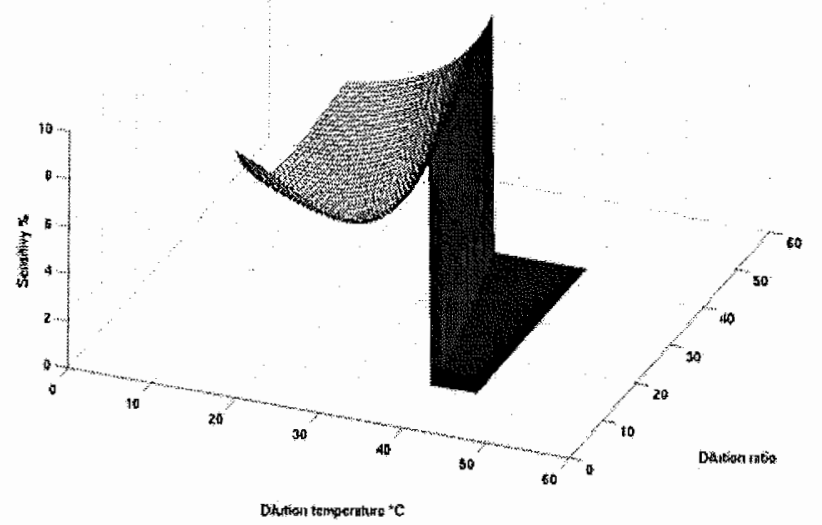

Figure 3: Sensitivity of number concentration of particles smaller than $0.026 \mu \mathrm{m}$ (nucleation mode) to particles larger than $0.026 \mu \mathrm{m}$ (accumulation mode) to DR changes in the order of \pm 1 and DAT changes of $\pm 0.5^{\circ} \mathrm{C}$. Sensitivity above DAT $40^{\circ} \mathrm{C}$ is cut off to see the minimum more clearly.

Nucleation mode characteristics also depend on the RT of the sample between sampling and analysis. Figure 4 shows the effect of residence time on the distribution obtained from a Euro $1 \mathrm{VW}$ Golf TDI driven at high load at $50 \mathrm{~km} / \mathrm{h}$. As residence time increases from 0.7 to $2.2 \mathrm{~s}$, nucleation mode becomes larger both in size and in concentration. Two competing phenomena take place as exhaust aerosol is kept at diluted conditions: volatile material is added from the gaseous to the particulate phase and existing particles coagulate due to their high concentration. The net effect of the combination of two phenomena cannot be predicted. In all cases where residence time increase has been examined, nucleation mode increases in size due to coagulation and condensation of new material. But number concentration can either decrease (coagulation prevailing) or increase (nucleation prevailing).

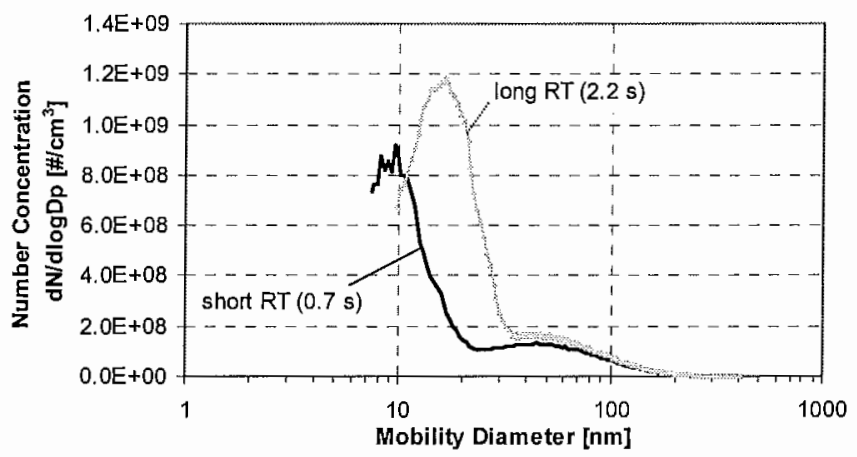

Figure 4: Effect of residence time on particle size distribution of a Euro $1 \mathrm{VW}$ Golf TDI. Residence time has been increased by introducing additional transfer line length after the primary dilutor (Driving condition: $50 \mathrm{~km} / \mathrm{h}$, Load: $7.6 \mathrm{~kW}$, DR: $\sim 25: 1, \mathrm{DAT}: 22^{\circ} \mathrm{C}$ ).

We have decided to impose a relatively high RT in our sampling system with use of the aging chamber (Figure 1). The decision has been taken for two main reasons. At first, a shift of nucleation mode to larger sizes facilitates sampling and analysis. As was presented in Figure 4 , the nucleation mode peak shifts to larger than $10 \mathrm{~nm}$ sizes. In this range, diffusion losses in the transport lines and instrumentation decrease while less sensitive and expensive CPCs (i.e. TSI 3010 instead of 3025) can be used. Secondly, it is expected that the sensitivity of the nucleation mode will decrease after a couple of seconds of formation because coagulation and nucleation may be extremely rapid after a few milliseconds of formation [1].

\section{AEROSOL CONDITIONS AT THE INLET OF DIFFERENT INSTRUMENTS}

Based on the decisions on sampling conditions, the geometry and flowrates in the sampling system, Table 1 summarizes the aging of the aerosol before it is analyzed by the different instruments. Conditioning is mainly translated to three parameters, total dilution ratio, temperature and residence time until instrument inlet. 
Table 1: Summary of sample conditioning for diesel aerosol before analysis with instrumentation

\begin{tabular}{|l|c|c|c|}
\hline & $\begin{array}{c}\text { Total Dilution } \\
\text { Ratio [-] }\end{array}$ & $\begin{array}{c}\text { Temperature } \\
{\left[{ }^{\circ} \mathrm{C}\right]}\end{array}$ & $\begin{array}{c}\text { Residence } \\
\text { Time [s] }\end{array}$ \\
\hline DGI & 12.5 & $\mathrm{~T}_{\text {amb }}$ to $\mathrm{T}_{\text {amb }}+5^{\circ} \mathrm{C}$ & 2.5 \\
\hline ELPI & 12.5 & $\mathrm{~T}_{\text {amb }}+\sim 10^{\circ} \mathrm{C}$ & 3.5 \\
\hline DC & 150 & $\mathrm{~T}_{\text {amb }}$ & 3.0 \\
\hline SMPS $^{*}$ & $10^{3}-15 \times 10^{3}$ & $\mathrm{~T}_{\text {amb }}$ & 3.5 \\
\hline CPC $^{*}$ & $10^{3}-15 \times 10^{3}$ & $\mathrm{~T}_{\text {amb }}$ & 3.5 \\
\hline
\end{tabular}

* lower range when using CPC 3025 and higher range when using CPC 3010.

\section{OPERATIONAL CHARACTERISTICS - PERFORMANCE}

\section{PRIMARY DILUTION STABILITY}

\section{Steady States}

The performance of a constant flow PFSS over a steady state condition is generally expected adequate. Indeed, Figure 5 shows a typical condition during steady state engine operation. There is no muffler or aftertreatment device installed on this engine and exhaust is sampled $1.5 \mathrm{~m}$ directly downstream of the exhaust manifold. All $\mathrm{CO}, \mathrm{CO}_{2}$ and $\mathrm{DC}$ signals are stable during the measurement with CoVs of $1.0 \%, 1.3 \%$ and $2.9 \%$ respectively. DR follows the stability of raw $\mathrm{CO}_{2}$ and presents similar CoV value.
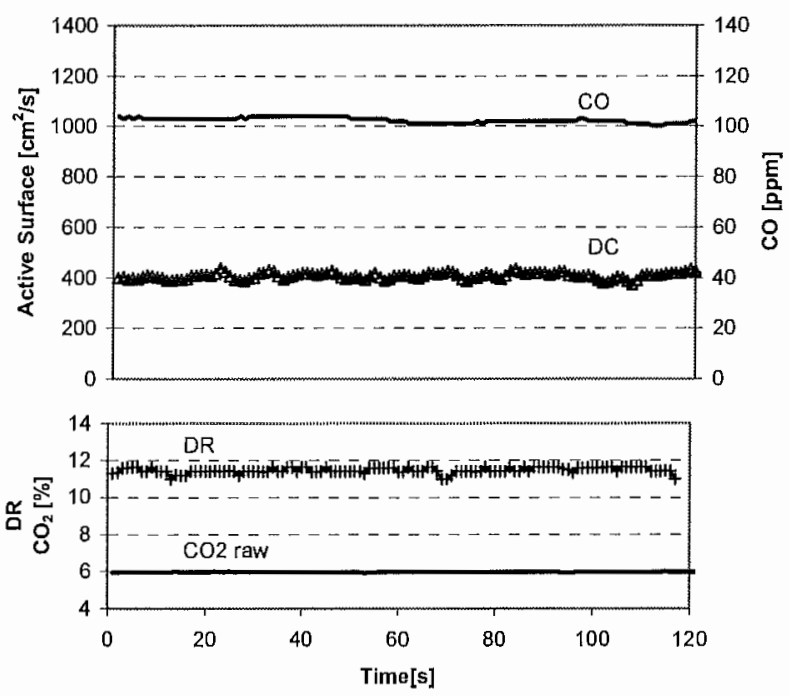

Figure 5: Stability of the $D R, C O$ and $D C$ signals over steady state operation of a VW TDI Euro 1 engine. Engine condition $1500 \mathrm{rpm}$, $80 \mathrm{Nm}$. Variation of engine speed and load is negligible.

However, setting of the dilution air and diluted sample flowrates may still lead to variable dilution ratios as engine operation conditions change. The upper panel in
Figure 6 shows the variance of the primary DR over the map of the same engine as in Figure 5 for steady state tests. The primary DR was set to $12.95: 1$ at $1500 \mathrm{rpm}$ and $25 \%$ load by adjusting the dilution air and diluted sample flowrates. Then the engine was scanned from $0 \%$ to $75 \%$ load from idle to rated speed and the DR was recorded with $\mathrm{CO}_{2}$ measurements without changing the flowrates of the dilution air or the diluted sample. It is seen that the DR decreases as load increases and reaches values as low as 5.5:1 in the most extreme case. This can only be possible if part of the dilution air escapes back in the tailpipe (backflow). Despite the fact that DR is constant (at a new value though) at each engine operation point, dependence of the DR on engine operation should be avoided because sampling conditions may still change with engine mode.
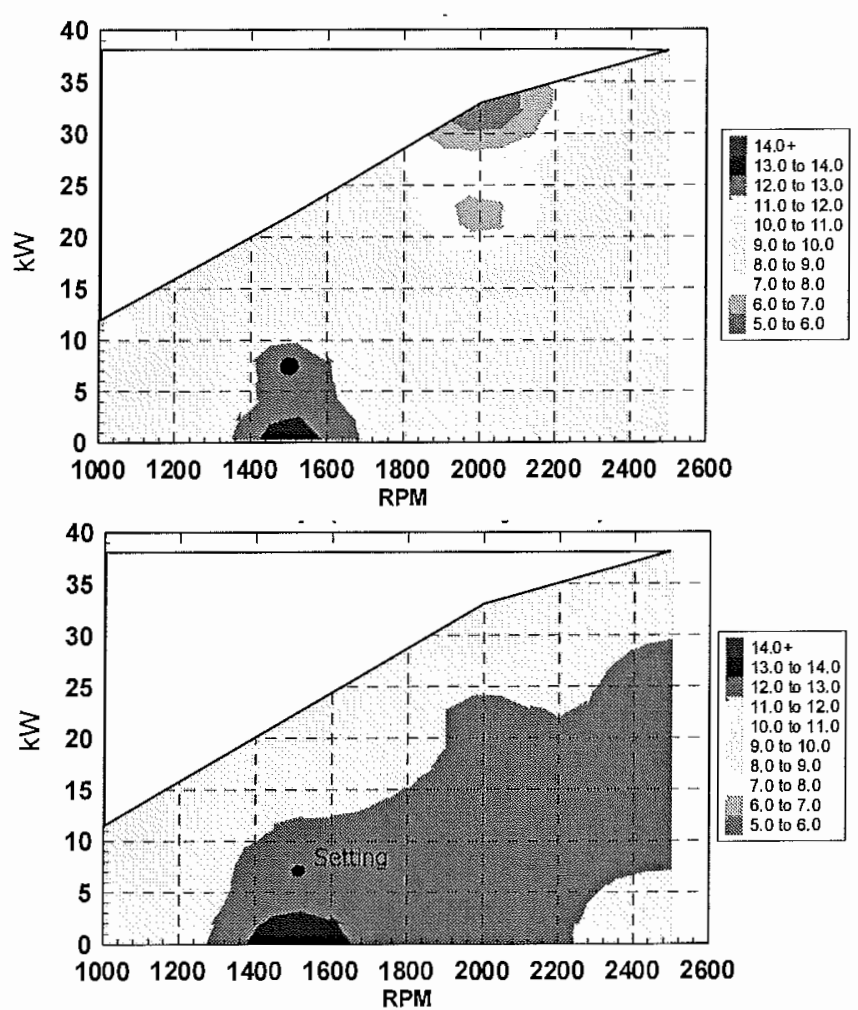

Figure 6: Effect of a WW Euro 1 TDI engine operating conditions on the DR of the primary porous dilutor. Upper panel: Sampling close to engine outlet ( $1.5 \mathrm{~m}$ downstream of exhaust manifold). Lower panel: Sampling at the end of a $5 \mathrm{~m}$ tailpipe with a DPF installed in the exhaust line in place of the exhaust muffler.

The condition in the upper panel of Figure 6 is an extreme case and it is mainly produced because of the hard sampling conditions close to the engine outlet. The lower panel shows the corresponding DR variation on the same engine after a DPF was installed in the exhaust line and sampling was performed $5 \mathrm{~m}$ downstream of the exhaust manifold. This is a typical tailpipe configuration for a diesel passenger car (assuming that DPF replaces the mufflers and catalyst). The DR was again set at 12.8:1 at the same operation condition as previously. In this case, the DR variance is in the range of $10: 1$ to $13: 1$ 
over the whole engine map which even extents beyond the range covered by the light duty vehicle cycles. Probably pressure pulsations which are attenuated when buffering the tailpipe are responsible for DR variance when sampling close to engine outlet. Based on these results, a good practice would always be to record the DR of any PFSS sampling from raw exhaust.

Quasi steady state conditions can be also established with vehicle testing on a chassis dynamometer. Figure 7 shows a typical steady state operation of the system, sampling exhaust from a VW Golf Euro 3 vehicle driven at $50 \mathrm{~km} / \mathrm{h}$, road-load. Although vehicle speed varies only in the range $49-51 \mathrm{~km} / \mathrm{h} \quad(\mathrm{SD}=0.6 \mathrm{~km} / \mathrm{h})$, a significant variation of the raw $\mathrm{CO}_{2}$ is recorded leading to a DR variation between 11-13:1. More impressively, the $D C$ signal shows a large variance $\left(S D=98 \mathrm{~cm}^{2} / \mathrm{s}\right.$ ) which is much larger than the engine steady state testing of Figure 5. Such unstable behavior should not be considered a sampling system defect but a representation of the fact that vehicle operation stabilization over a steady speed is usually not as successful as engine stabilization (on an engine dyno) and hence conclusions drawn from vehicle steady state testing should always be treated with caution. This variable pattern at constant speed may be more or less pronounced depending on engine technology characteristics (e.g. compare variability levels over constant speed tests in the work of ACEA [22]).

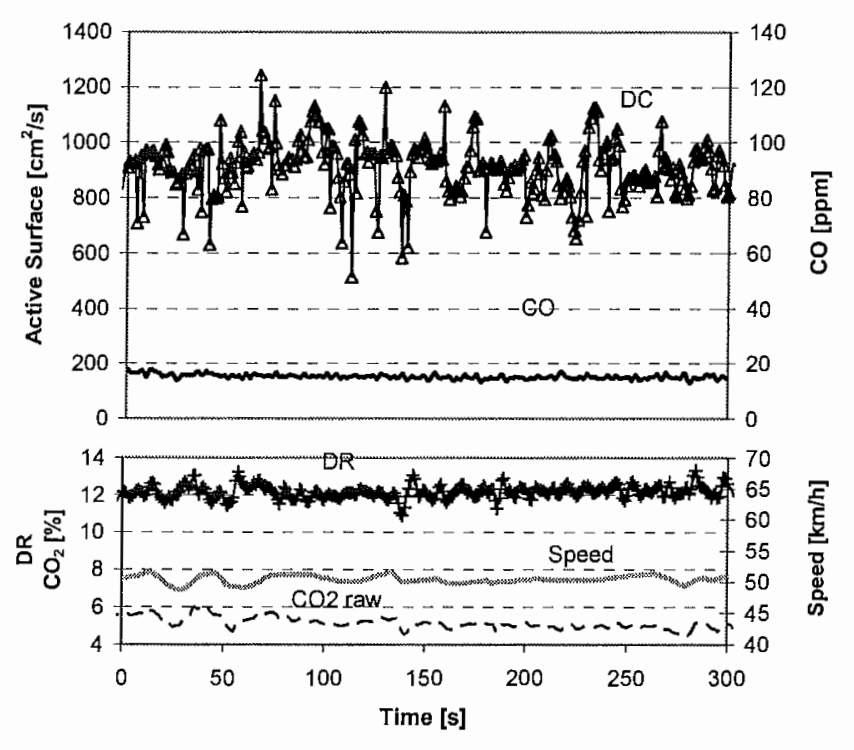

Figure 7: Stability of the DR, $C O$ and $D C$ signals over steady state operation of a WW Golf Euro 3 vehicle. Variations for the four signals, expressed as CoVs are DR: $2.8 \%, \mathrm{DC}: 10.8 \%, \mathrm{CO}: 5.2 \%, \mathrm{CO}_{2 \text {, raw: }}$ $5.9 \%$ over the period of two minutes recording.

\section{$\underline{\text { Transients }}$}

Results over transient tests need to be collected in order to derive vehicle emission performance in real-world driving conditions. In a constant flow PFSS, DR needs to be determined, in order to reduce the signals measured by the instruments to raw exhaust and then to calculate total vehicle emissions. However, tests such as the ones in Figure 6 show that DR may change for different vehicle driving conditions and therefore DR needs in principle to be provided in real time. This can be made possible by measuring raw and diluted $\mathrm{CO}_{2}$ (or $\mathrm{NO}_{\mathrm{x}}$ ) concentrations.

Figure 8 shows the DR of two similar vehicles (VW Golf TDI equipped with oxidation catalyst - one is Euro 2, the other is Euro 3), determined with $\mathrm{CO}_{2}$ measurements of raw exhaust and diluted sample in two different facilities. DR setting at steady state is $12.5: 1$ in both cases, achieved with the same configuration and flowrates in the PFSS. In both cases there are some extreme peaks in the DR recorded which are associated with fuel cut-off periods during decelerations. These occur because $\mathrm{CO}_{2}$ concentration goes to zero during these events and the DR cannot be defined. Additionally, there are differences in the DR pattern. The lower panel shows a more busy pattern which can be averaged around the set value. The upper panel shows a smoothened behavior where fluctuations of larger period occur. These differences can be clearly associated with gaseous analyzers response. Faster analyzers and shorter transfer lines are used in the latter case, which faster respond to $\mathrm{CO}_{2}$ changes. Analyzers of lower time response are used in the former case. Finally, raw and dilute sample signals are recorded in different locations and their synchronization is required before DR is calculated. All these uncertainties in estimating time lags, analyzer responses and time drifts during the measurement may significantly affect DR calculation.
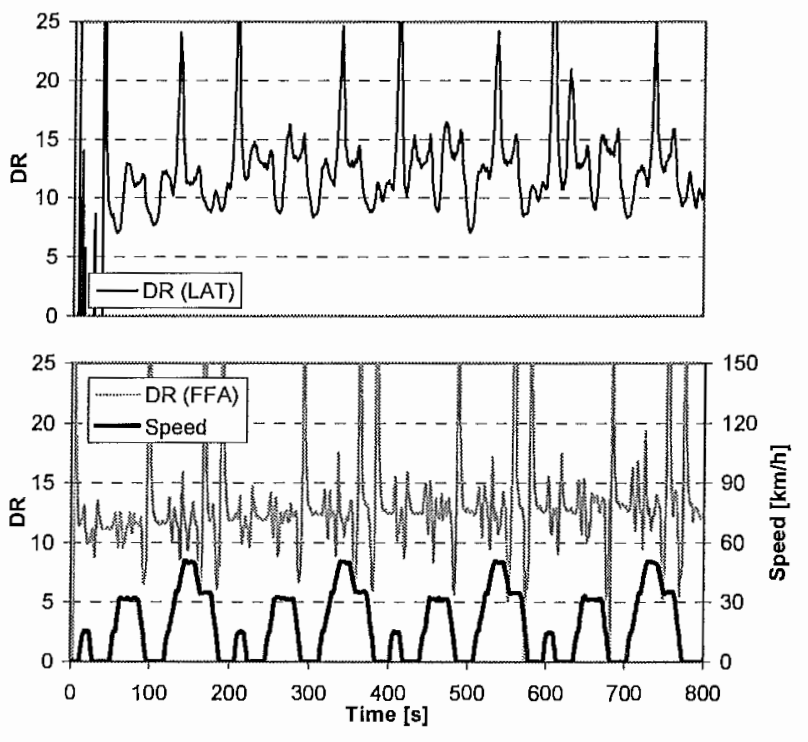

Figure 8: DR variation over an Urban Driving Cycle, using two similar vehicles (LAT: Euro 2 WW Golf, FFA: Euro 3 WW Golf) but different $\mathrm{CO}_{2}$ measurement setup. DR setup is at roughly $12.5: 1$ for both cases. Speed pattern over cycle shown in lower panel. 

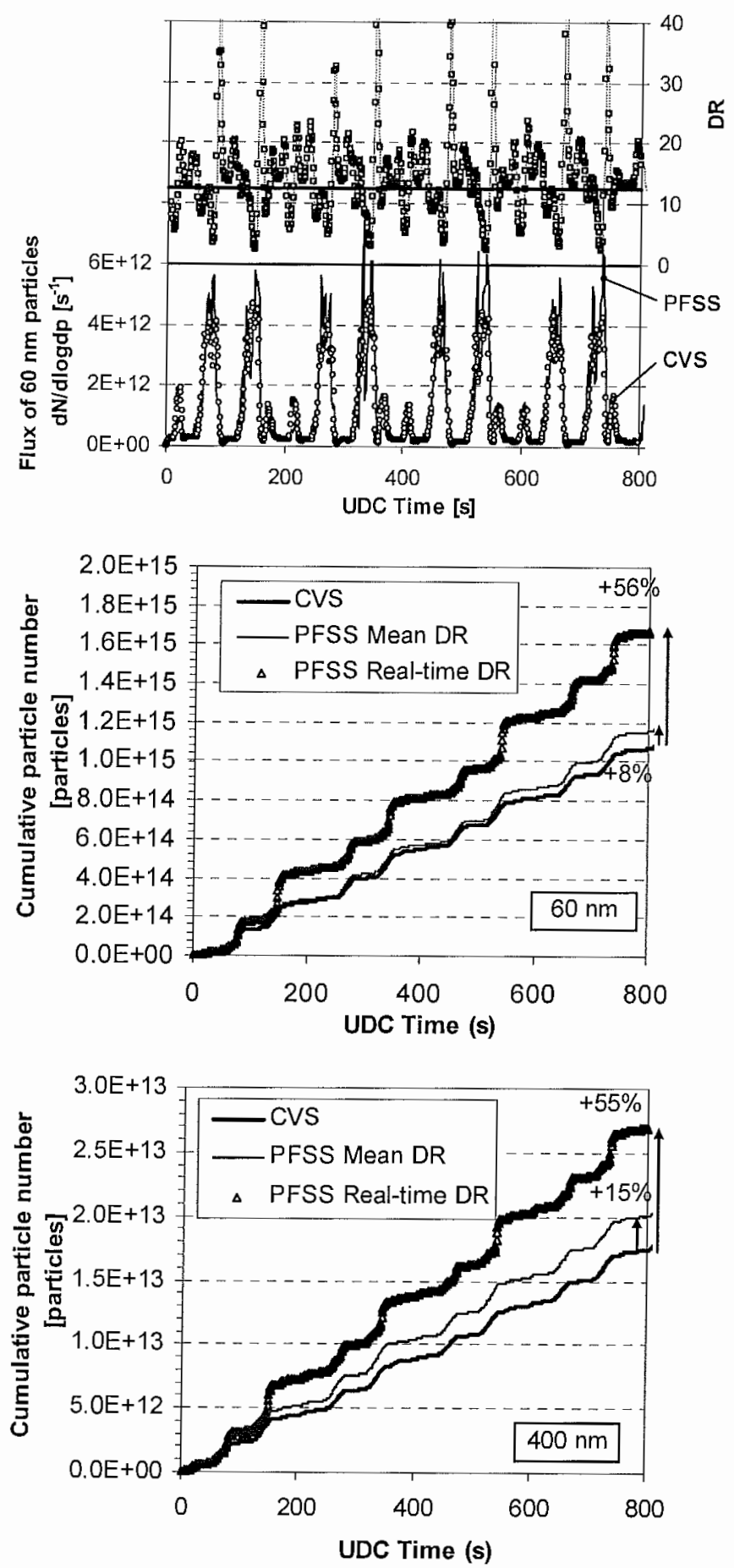

Figure 9: PFSS vs CVS comparison over a UDC test. Upper panel: Flux of $60 \mathrm{~nm}$ solid particles (downstream of TD) measured with the ELPI sampling from the PFSS dry branch and from the CVS. The real-time $\mathrm{CO}_{2}$-based $\mathrm{DR}$ is also shown on the top part of the panel. Middle panel: Cumulative flux of $60 \mathrm{~nm}$ particles measured in the CVS and assuming a constant DR of 12.4:1 or assuming the real-time DR. Lower panel: Cumulative flow of $400 \mathrm{~nm}$ particles in the CVS and calculated with two DR estimations as before.

In order to overcome the problems associated with the calculation of a real-time $D R$, it was decided to use a single value throughout the test cycle. We can estimate this single value from the short steady speed conditions of the UDC cycle (at 17, 35 and $50 \mathrm{~km} / \mathrm{h}$ ). This is examined in the upper panel of Figure 9 . In this case solid particles of $60 \mathrm{~nm}$ were measured at the CVS and at the tailpipe using the PFSS. Also, the DR of the PFSS was calculated in real-time with $\mathrm{CO}_{2}$ concentrations. Since signal synchronization is critical for such comparisons, the signal from a fast-response oxygen sensor placed in the exhaust line was used as reference in this particular experiment. All measured signals $\left(\mathrm{CO}_{2}\right.$, aerosol instruments, etc) were then synchronized against the oxygen sensor, with the objective to match as close as possible the timing of its response. On the other hand, the DR value calculated over the UDC steady speed periods corresponds to a value of 12.4:1 (bold horizontal line). The cumulative emissions as a function of UDC time are shown in the two lower panels of Figure 9 for two particle sizes. There is a satisfactory agreement between the CVS and the PFSS values when a mean DR is used, while use of the real-time DR results to significantly higher values (more than $50 \%$ difference).

There is still a difference between CVS and PFSS for $60 \mathrm{~nm}$ and $400 \mathrm{~nm}$ particles when using a constant DR. This may occur due to usual experimental uncertainties or because there is indeed some particle loss in the CVS. Another reason could be the possible different effective density of soot particles in the CVS and the PFSS [23] which is a function of particle size. As ELPI response depends on the effective density value, this can also explain the difference in the deviations for different particle sizes.

This comparison demonstrates that a constant $D R$ value should be used over a transient test. DR estimations in real-time with $\mathrm{CO}_{2}$ concentrations using conventional gaseous analyzers may lead to large uncertainties and subsequently a great overestimation of the correct total value.

\section{SECONDARY DILUTION EFFECTS}

Ejector dilutors have been widely used for conditioning of the exhaust aerosol, even as primary dilutors sampling directly from raw exhaust [13]. In an ejector dilutor a vortex is formed in the venturi region which may have an effect on the particle distribution and particle losses. Cheng et al. [24] found little losses in ejector dilutors operating with turbulent mixing. However, it is worth examining the performance of ejector dilutors in the case of diesel exhaust.

The upper panel in Figure 10 shows two distributions of diesel exhaust measured upstream and downstream of an ejector dilutor. In these measurements a Renault Laguna Euro 3 vehicle was driven at $50 \mathrm{~km} / \mathrm{h}$ and $120 \mathrm{~km} / \mathrm{h}$ on road load. Primary sampling conditions were set to DR $12.5: 1$ and DAT $32^{\circ} \mathrm{C}$ and an SMPS $3936 \mathrm{~L}$ with a CPC 3010 was used to record distributions. Upstream sampling was conducted in the outlet of the first of the two cascaded ejector dilutors and downstream sampling in the outlet of the second 
cascaded ejector dilutor. CPC was operating in countmode in both cases $\left(<10^{4} \mathrm{~cm}^{-3}\right)$. In both cases of a mono-modal $(50 \mathrm{~km} / \mathrm{h})$ and bi-modal $(120 \mathrm{~km} / \mathrm{h})$ distribution, the ejector dilutor seems not to affect the shape of the distributions and especially the distinct nucleation mode is preserved.

The lower panel in the same figure shows the normalized ratio of upstream over downstream ejector distributions as a function of particle size. The continuous line corresponds to the SMPS scans while the solid points correspond to measurements conducted with the CPC sampling monodisperse aerosol downstream of the DMA. Variations are in the order of $\pm 5 \%$ and show little dependence on particle size. There is a more significant effect for particles in the two ends of the distribution. It cannot be concluded if this is a true ejector effect or an outcome of the combined uncertainty of small particle size and time lag between the SMPS measurements. The DMA+CPC measurements do not show a similar tendency. In any case, it is important to emphasize that both the nucleation and accumulation mode shapes are transferred intact through the ejector dilutor.
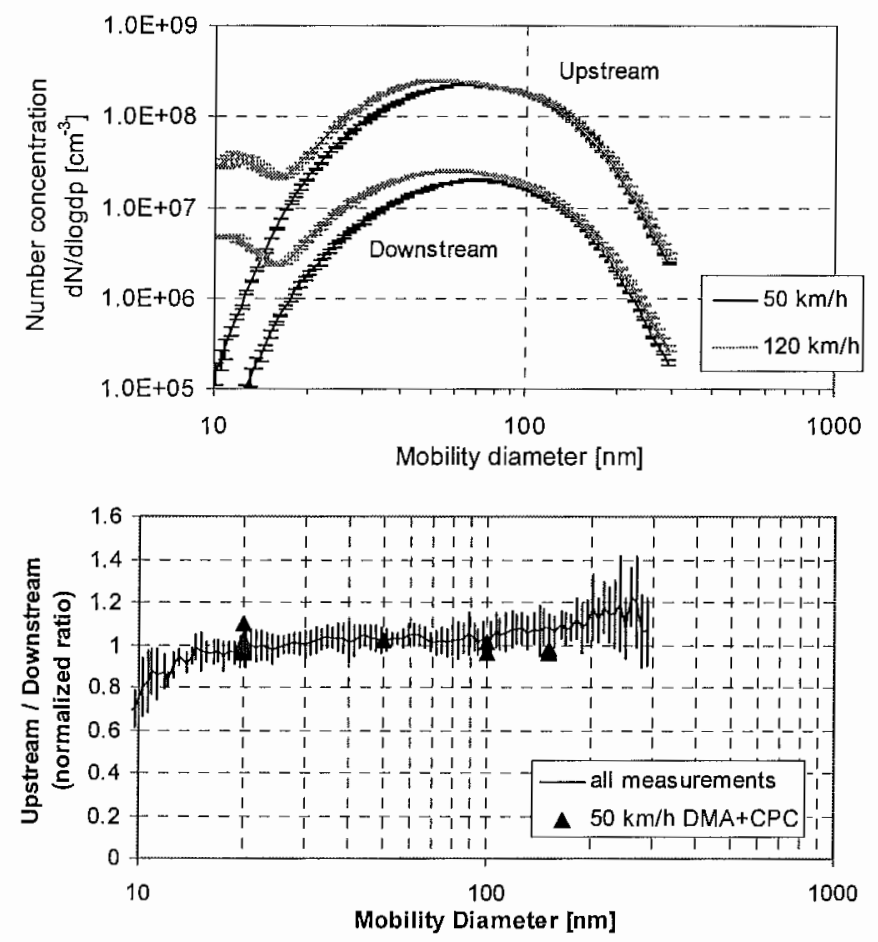

Figure 10: Effect of secondary ejector dilutors on the distribution of particles. Upper panel: Effect of one ejector dilutor on SMPS distributions obtained at $50 \mathrm{~km} / \mathrm{h}$ and $120 \mathrm{~km} / \mathrm{h}$ using a Euro 3 Renault Laguna. Lower Panel: Normalized ratio of upstream and downstream distributions obtained with SMPS scans ( 7 scans at $50 \mathrm{~km} / \mathrm{h}$ and 4 scans at $120 \mathrm{~km} / \mathrm{h}$ ) and CPC concentrations sampling monodisperse aerosol in the outlet of a DMA.

Care has to be taken to either clean or calibrate the ejector dilutors in regular intervals when in use. In Figure 11 , an example of calibration is given when the ejector dilutor has been just cleaned in an ultrasonic bath and after $25 \mathrm{~h}$ of operation. Over this period, it is estimated that about $20 \mathrm{mg}$ of PM have been drawn through the ejector dilutor. Measurement of the DR was conducted with $\mathrm{NO}$ in $\mathrm{N}_{2}$ and different sample inlet pressures were used. The calibration shows that DR increased by almost three units ( 20\%) for ambient sample pressure. This is presumably due to soot accumulation on the dilutor nozzle which changes the nozzle geometry. In this respect, ejector dilutors were not used for prolonged time periods without cleaning (i.e. ultrasonic bath cleaning preceded any new vehicle measurement) and a calibration with gases was routinely performed during the measurement campaign.

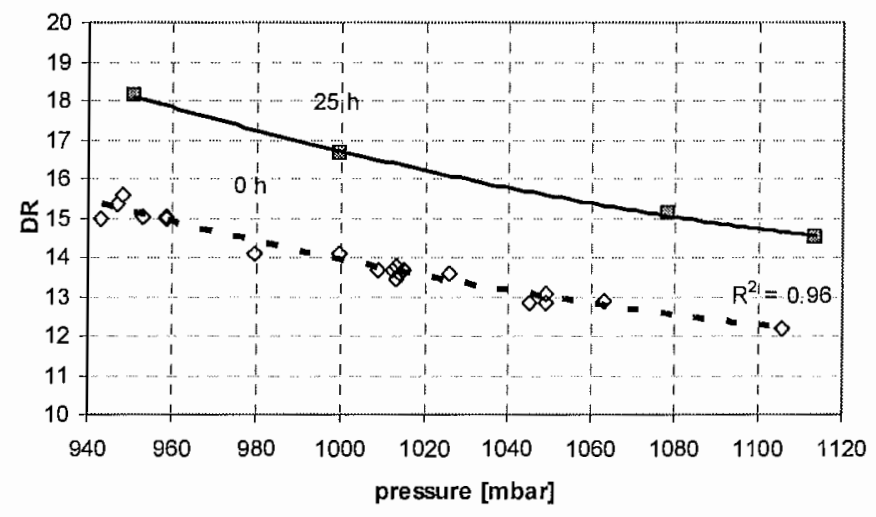

Figure 11: Effect of the ejector dilutor history on the DR provided as a function of sample inlet pressure. DR increases by several units as the ejector dilutor operates. After $25 \mathrm{~h}$ some $20 \mathrm{mg}$ of airborne PM have been diluted in the ejector dilutor.

\section{THERMODENUDER PERFORMANCE}

The operation of the TD was examined sampling both nucleation and accumulation mode diesel particles, with the VW Euro $1 \mathrm{TDI}$ engine. Figure 12 shows the results of an experiment performed to examine the denuder performance with a DR of $\sim 5: 1$. It should be stressed that it is expected that sampling at this low DR increases the volatile material concentration and imposes difficulties to the TD because it reduces its efficiency and shortens the lifetime of the active charcoal. In addition to the vehicle test data, the upper panel of Figure 12 shows solid particle losses determined with $\mathrm{NaCl}$ aerosol by the manufacturer [25]. Losses are higher for smaller particles due to thermophoresis and diffusion to the adsorber walls. Although such losses have been determined with particles different than soot, it is expected that soot particle losses will be similar when size is expressed as mobility diameter.

The middle panel shows two measured distributions recorded upstream and downstream of the TD with the SMPS. There is a distinct nucleation mode formed in the upstream distribution which disappears downstream the TD. There is also a reduction in the peak concentration 
of the accumulation mode which comes from solid particle losses. The downstream distribution is then corrected for solid particle losses, according to the manufacturer's data. In this case, the upstream and downstream accumulation modes match in concentration while the significant reduction of the nucleation mode is obvious and a rather log-normal distribution is formed. It is also interesting to note that the peak size of the accumulation mode decreases in the downstream distribution (69 instead of $76 \mathrm{~nm}$ ). This may be due to removal of adsorbed material from the agglomerated particles surface.
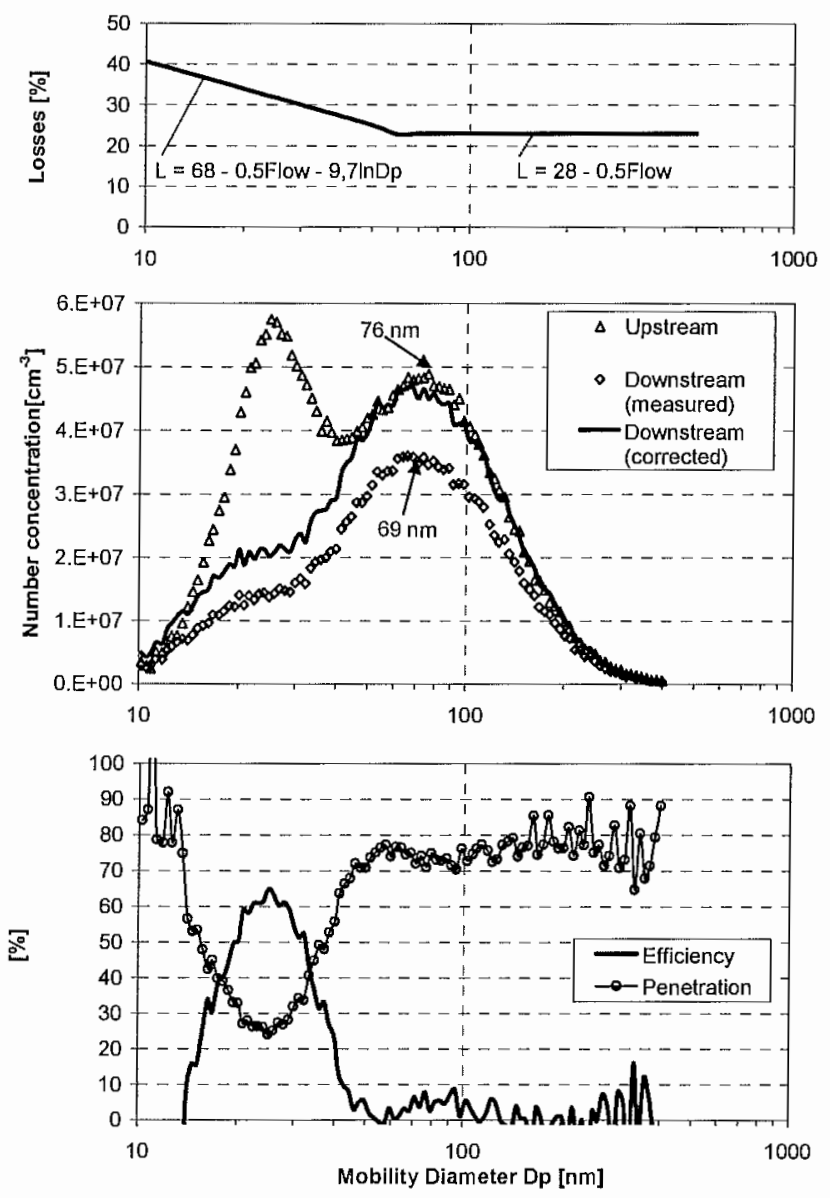

Figure 12: TD performance in nucleation mode suppression, operating at a sample flowrate of $10 \mathrm{l} / \mathrm{min}$. Upper panel shows solid particles losses in the denuder determined by the instrument's manufacturer. Middle panel shows an upstream and downstream distribution also corrected for losses. Lower panel provides "penetration" and "efficiency" performances.

The lower panel in Figure 12 shows different expressions of the TD performance. The term "penetration" is customarily used to express the ratio of measured downstream vs. upstream concentrations. Penetration is lower than $100 \%$ because of volatile particles removal and solid particle losses. However, penetration is not an appropriate expression for TD performance evaluation. $A$ TD is used to primarily remove nucleation mode particles and its efficiency should be higher in these sizes. We may then express TD efficiency as the ratio of particles retained by the TD over the upstream concentration, after correction for solid particle losses. This is shown with the "efficiency" curve in the same figure. Efficiency is minimal for the accumulation mode where no individual volatile particles are present and substantially increases for volatile nucleation-mode particles. This expression shows that as long as solid particles losses have been corrected for, the TD does not seem to affect the accumulation mode, while efficiently removing volatile nanoparticles.

Similar TD devices were also evaluated in the framework of the UK PMP programme [26]. This project concluded that TD performance was reproducible from day to day and that the two different devices tested behaved similarly. This agrees with experimental evidence from "Particulates". Penetration curves presented in Figure 12 match the ones derived in PMP, although a light duty vehicle was used in this study and a heavy duty engine operating on different fuels was employed at PMP. However, PMP raised concerns for the TD suitability for solid particles separation, especially when in cases of low solid particle concentrations (i.e. from DPF equipped vehicles). Our indicative results provide clear indication that the TD performance may be predicted at least for conventional diesel vehicles. When a DPF is used, solid particle concentrations reach background levels which do not allow a reliable evaluation of TD performance. In such delicate measurements, evaluation of the TD performance would require back-to-back tests with alternative solid particle separation methods (e.g. hot dilution) to obtain absolute levels of solid particle concentrations. In any case, we never encountered any nucleation mode penetration or low TD efficiency throughout the measurement campaign, even when measuring DPF equipped vehicles.

\section{OVERALL LOSSES}

The losses in the sampling system need to be quantified in order to be able to compare particle properties obtained with different instruments. A model has been built which calculates losses in the different components of the sampling and transport lines. This model has been applied in the exact configuration of the system setup in all laboratories in the project. However, operation of the sampling system under similar flowrates in all laboratories simplifies corrections.

Figure 13 shows the overall particle transport efficiencies (penetrations) calculated to the different instruments for a typical sampling set-up. The model takes into account diffusional and inertial losses in the tubes and inertial losses in bends. There are a few equations in the literature to calculate transport efficiencies in laminar and turbulent flows $[27,28]$. In our case, a turbulent flow is established in the main line from the primary dilutor to the DGI and laminar flows in the secondary transfer lines, at least according to the calculated Reynolds numbers. Aerosol flows however may be turbulent even 
over the transitional region due to secondary flows and perturbations induced by bends, fittings, etc. However, the relatively high $R_{e}$ numbers established $\left(\operatorname{Re}_{d}>1000\right)$ decrease the contribution of diffusional losses in bends [29]. In order to correct for losses we have decided to use laminar flow corrections for $\mathrm{Re}_{\mathrm{d}}<2000$ and turbulent flow corrections for $R_{d}>4000$. A weighted average is used for the transitional region $\left(\mathrm{Re}_{\mathrm{d}}\right.$ between the two limits). Different transport efficiency formulae can be found in the literature. Although, there are no large deviations between the formulae proposed, an average of worst and best cases has been used. Additionally, a $99 \%$ penetration was considered for each ejector dilutor.

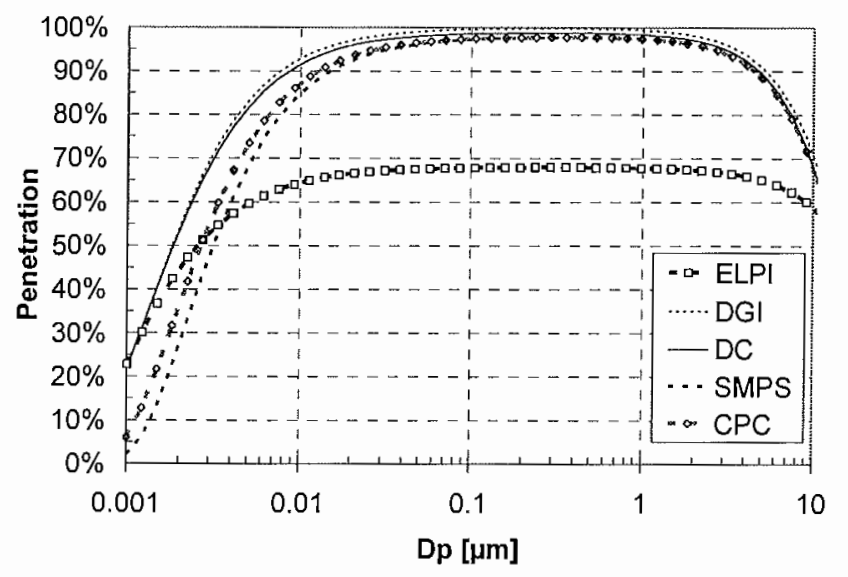

Figure 13: Calculated penetration as a function of particle size for transfer lines to different instruments. The low penetration for the ELPI is due to TD losses.

The model calculates transport efficiencies above $90 \%$ for all particles in the range $0.01 \mu \mathrm{m}$ to $1 \mu \mathrm{m}$, which are of interest to this study. Only exception is the dry branch where the TD introduces significant particle losses and transport efficiency to the ELPI does not exceed $70 \%$. This correction has been introduced to the ELPI results as a function of geometric mean diameter for each impactor size. However, size-dependent corrections for the $\mathrm{DC}$ and the CPC are not possible to introduce due to their size-specific character. The effect of these losses will be greater to CPC which is equally sensitive to small and larger particles. Figure 14 shows the effect of losses on two distributions, one with and one without nucleation mode. Maximum correction to the total concentration of the SMPS occurs when nucleation mode is present and is in the order of $\sim 6 \%$. Therefore, the maximum deviation of CPC measurement from the "true" value should be in this order of magnitude. DC deviation would be much lower than that. Such effects further justify the decision to use a long residence time in the sampling system.

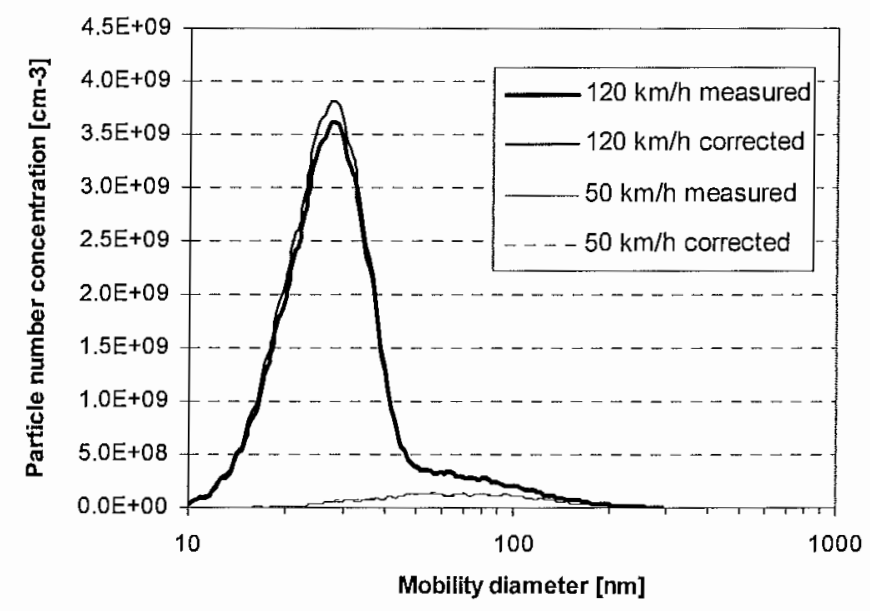

Figure 14: Effect of losses on a distribution without nucleation mode $(50 \mathrm{~km} / \mathrm{h})$ and with nucleation mode $(120 \mathrm{~km} / \mathrm{h})$. Measured number concentrations are $3.5 \%$ and $5.7 \%$ lower that the corrected values.

\section{REPEATABILITY}

With the term "repeatability", one refers to the precision by which measurements are conducted within one physical environment (laboratory) using the same methods and principles. Repeatability should be distinguished from "reproducibility" which should be used to characterize the consistency in measurement results between different laboratories. Generally, mass of PM and associated properties are considered to be poor performers with regard to repeatability, especially compared to gaseous pollutants $\left[30,{ }^{31}\right]$. The complexity of exhaust particle nature and its sensitivity to sampling conditions are responsible for such a behavior.

We examine here the repeatability of particle size distributions sampled with the PFSS. Figure 15 shows the performance in different occasions. The upper panel presents the repeatability of SMPS using 18 scans in total recorded over a period of two months (two scans per day over nine different days) on the VW Euro 1 TDI engine at $1500 \mathrm{rpm}, 40 \mathrm{Nm}$. Measurements were performed downstream of the thermodenuder and correspond to solid particles only. All distributions are corrected for primary and secondary DRs. There is a very satisfactory repeatability both of the number concentration and size distribution of the distribution. The CoV of the number concentration as a function of size is shown on the right axis. CoV values remain below $25 \%$ for the whole particle range. The middle panel of the same figure shows SMPS repeatability corresponding to particle size distributions of the Euro 3 Renault Laguna using 8 scans collected over a period of 2 months (two scans per day over four different days). The vehicle was driven at $50 \mathrm{~km} / \mathrm{h}$, using road load. CoV values are again satisfactory over almost the whole range of particle distribution. They increase in both ends of the distribution due to the low average concentration values. 

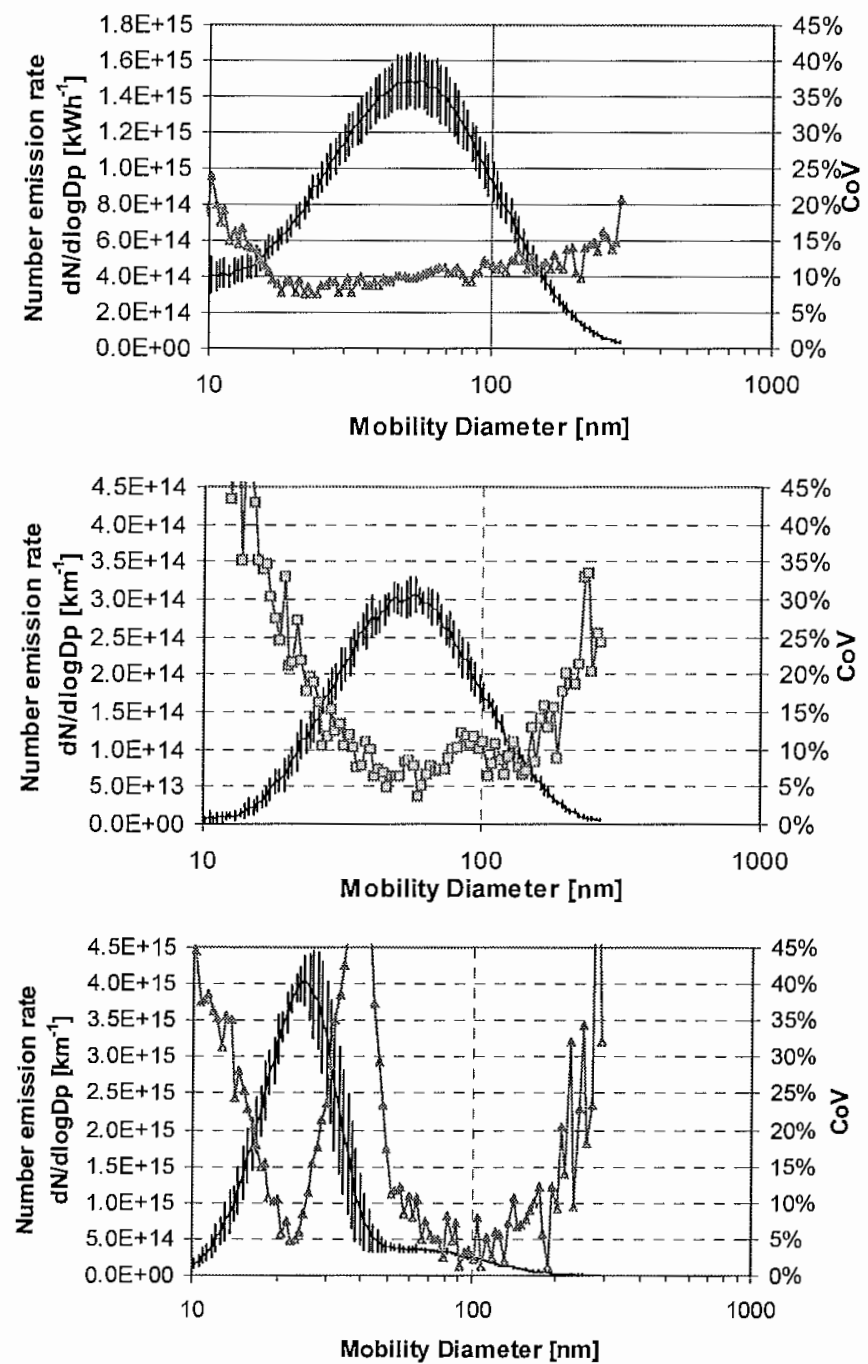

Figure 15: Repeatability of measurements examined with different aerosol properties. Upper panel: 18 scans of solid particle distributions. Middle panel: 8 SMPS scans of total particle distribution. Lower panel: 4 SMPS scans including nucleation mode particles. Error bars correspond to a standard deviation around the mean value.

Finally, the lower panel shows repeatability over a much shorter period of two consecutive days on the same Renault Laguna driven at $120 \mathrm{~km} / \mathrm{h}$ to produce nucleation mode particles. Despite the repeatable sampling conditions and the short period examined, nucleation mode particles are found to be much more variable than the accumulation mode ones. For this particular case, there is a high variation especially in the decreasing tail of the nucleation mode. Experience shows that vehicle conditioning is critical for the nucleation mode, in addition to sampling conditions. In those two consecutive days, the second scan nucleation peak was always lower than the first scan. Prior to the $120 \mathrm{~km} / \mathrm{h}$ measurement the vehicle was measured at $90 \mathrm{~km} / \mathrm{h}$. Shifting from a low to a high load condition is generally expected to initially enhance nucleation mode due to desorption phenomena in the tailpipe, and then nucleation mode gradually decreases. Hence, evaluation of the system performance using nucleation mode to examine repeatability is questionable, following a passenger car conditioning protocol. Results might have looked differently studying nucleation mode over e.g. heavy duty engine steady-state operation.

\section{REPRODUCIBILITY}

The same VW Golf Euro 3 was measured in two different laboratories (Shell Global Solutions, UK and Ford Forschungszentrum, Germany) using different prototype sampling systems of the same specifications and the same measurement protocol. A third, similar but not the same, vehicle was measured at AVL MTC (Sweden) using a third sampling system. Comparisons between the three labs may provide a good picture of the reproducibility of the results.
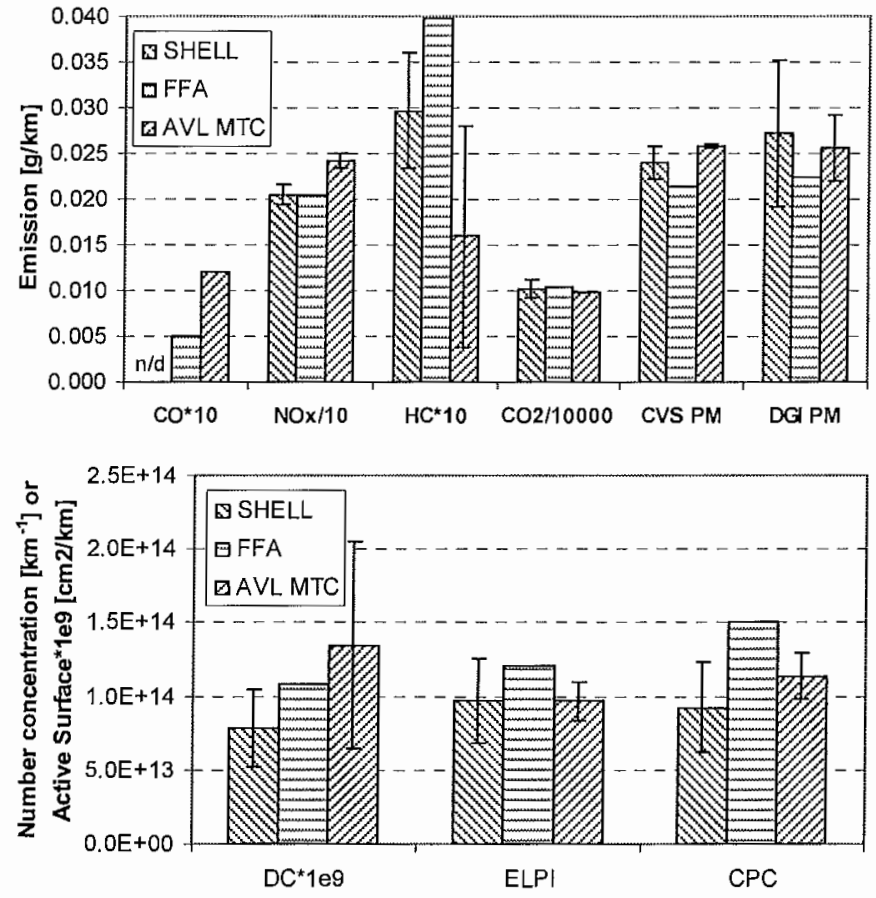

Figure 16: Reproducibility of gaseous pollutants and different particle properties in three different environments (Shell UK, Ford Forschungszentrum Germany, AVL MTC Sweden), Measurements conducted on similar WW Golf Euro 3 TDI vehicles. Upper panel: Comparison of conventional pollutants and DG! total mass at $50 \mathrm{~km} / \mathrm{h}$. Lower panel: Comparability of different aerosol instruments.

Figure 16 shows the comparison between conventional pollutants and different particle properties measured driving the vehicles at $50 \mathrm{~km} / \mathrm{h}$. There is very good repeatability in $\mathrm{CO}_{2}$ between all labs, as one should expect. $\mathrm{CO}$ and $\mathrm{HC}$ are not the best indicators of reproducibility due to their extremely low levels for the particular vehicle, which reach below detection levels in one of the cases reported. NOx, PM and DGI results show similar variability, in the order of $20 \%$ (expressed as $\mathrm{CoV}$ ), a fact that can be explained either by experimental uncertainties or differences in the setup. 
There is also satisfactory agreement in the aerosol properties measured with different instruments. ELPI especially, measuring particles from the dry branch, shows CoV values of less than $20 \%$. CPC and DC reach COV values up to $40 \%$ for this steady state speed.

Reproducibility was further improved for results obtained over the reference procedure. Over the cold-start NEDC tests, CoV values from the three laboratories reached below 20\% levels for all instruments (PM, CPC, DC, ELPI). Based on such a comparison, one may in generally establish a good baseline for comparison of particle properties obtained in different laboratories. There are generally no widely reported results for aerosol properties comparability measured in different laboratories. However, reproducibility in the range of $\pm 20 \%-30 \%$ (for mean absolute values and depending on the instrument) should be considered satisfactory for such sensitive measurements.

\section{APPLICATIONS AND VALIDATION}

\section{COMPARISON BETWEEN CVS AND GRAVIMETRIC IMPACTOR}

A useful comparison to check the overall performance of the PFSS is to compare the total mass collected in the DGI with the PM collected with the reference procedure. Figure 17 shows such a comparison for the VW Golf TDI Euro 3 vehicle for a range of steady state and transient tests. Looking first at steady states $(50$ to $120 \mathrm{~km} / \mathrm{h}$ ), a fairly good agreement between the DGI total mass and CVS PM can be seen. The range of variation is in the order of $-15 \%$ to $10 \%$. There is a consistent underestimation over the transient tests. As explained in a previous section, a constant sample flowrate sampling system should be expected to underestimate non steady-state measurements. This is a physical limitation of the sampling principle. On the other hand, the good comparability with the CVS shows that vehicle exhaust flowrate and DR of the PFSS can be correctly taken account for.

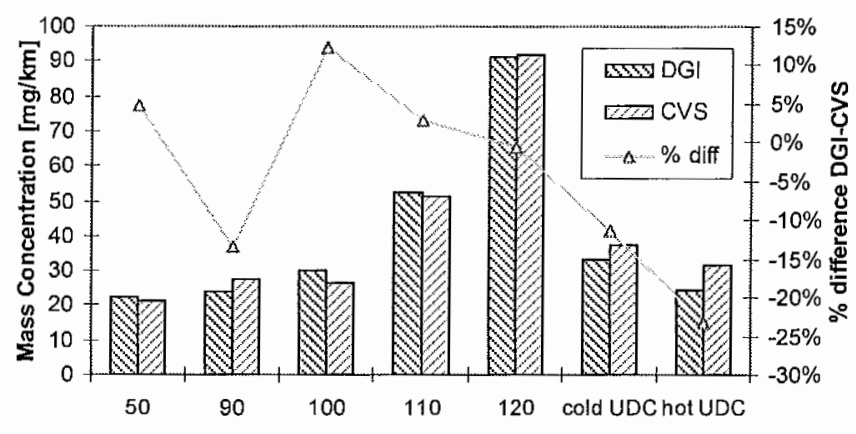

Figure 17: Comparison of PM collected with the reference procedure (CVS) and the DGI in the PFSS. WW Golf TDI Euro 3 measured in different driving speeds and transient cycles.
COMPARABILITY BETWEEN WET AND DRY BRANCH AND COMBINATION OF INSTRUMENT INFORMATION IN REAL TIME

ELPI in the dry branch is used to aerodynamically classify aerosol particles and measure their number concentration. In the wet branch, the SMPS provides the same information as a function of the particle mobility diameter, for steady state tests. Figure 18 compares the mean geometric diameter given by the two different distributions. A third mean diameter estimation is given by combining the number concentration provided by the $\mathrm{CPC}$ and the active surface of the DC.

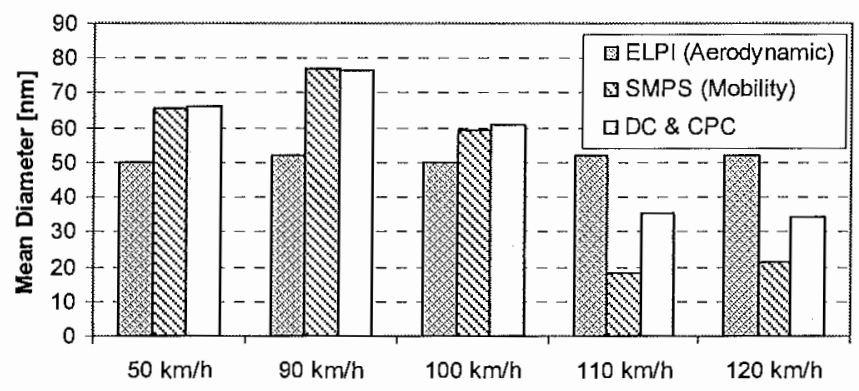

Figure 18: Comparison between particle diameter expressions obtained with the ELPI in the dry branch (aerodynamic), the SMPS at the wet branch (mobility) and combination of DC and CPC measurement at the wet branch (mobility).

In steady state tests when no nucleation occurs (50 $100 \mathrm{~km} / \mathrm{h}$ ) the mean aerodynamic diameter appears smaller than the mobility one. This has recently been explained with the concept of the effective density [32, 33]. In practice, the effective density is a combined measure of particle bulk density and voids included in an envelope volume. The effective density is a useful measure because it can be used to correlate particle inertial and diffusional behavior and may be important to determine for soot aerosol. This example shows that parallel comparisons of dry ELPI and SMPS can be used to determine such a property. Another interesting effect is that the ELPI mean diameter of dry soot mode is basically constant at different operating conditions, despite the variance of the mobility diameter of total (solid and volatile) particles. This can be explained by attributing a signature size distribution for dry soot particles.

More impressively, there is a very good match between the SMPS derived mean diameter and the one derived by the DC and CPC. Further to being a very good cross check for the measurement, this finding also means that mean diameter can also be determined in real time. There are constraints though: when a nucleation mode occurs, as in the case of $110 \mathrm{~km} / \mathrm{h}$ and $120 \mathrm{~km} / \mathrm{h}$, the actual SMPS mean diameter decreases more than the one derived by the active surface. This is because a bimodal distribution cannot be reconstructed by only active 
surface and number concentration values, hence the distinct contribution of the nucleation mode is not clearly represented.

Both the DC and the ELPI utilize a corona unipolar charger to charge airborne particles. The chargers are of similar concept and configuration. Hence, the current induced to particles can be compared in the two cases. This is attempted in the upper panel of Figure 19 where real-time signal of the two instruments is shown over a cold-start UDC. As mentioned above, all signals were recorded on the same computer and synchronized using as reference the signal of a fast-response oxygen sensor placed at the exhaust pipe. Dedicated software takes into account the different transport delays from different instruments and performs all necessary calculations. ELPI is located in the dry branch and DC in the wet one. Total current from the DC corresponds to particles smaller than $1 \mu \mathrm{m}$ because an impactor is located upstream of the corona charger. To compare this signal we sum up ELPI currents from filter stage up to stage 7 $\left(d_{50 \%}=1.04 \mu \mathrm{m}\right)$. Both diffusion and space charge losses have been corrected for. There is a fairly good agreement of the two currents. Looking the picture in detail, it is shown that $D C$ produces higher values during the first $\sim 100 \mathrm{~s}$ (cold-start) seconds of the cycle and over accelerations. These deviations from ELPI current are indications of volatile particle formation.

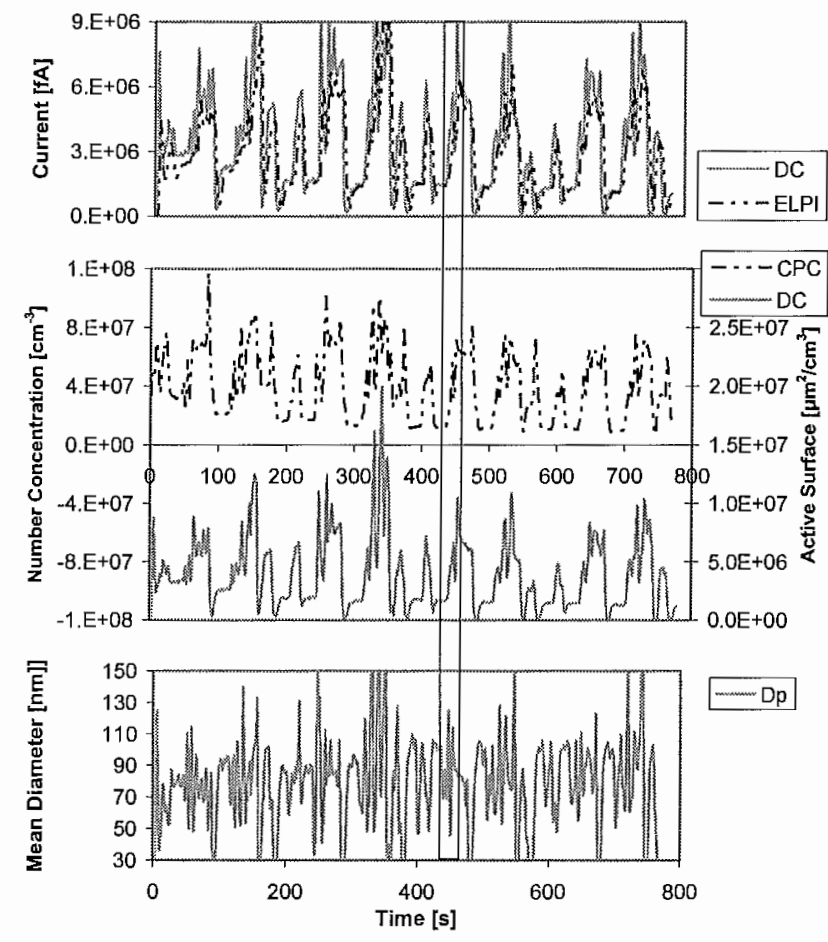

Figure 19: Comparison of different instruments in real-time. Upper panel: DC and ELPI signals in the wet and dry branch respectively over a UDC test. Middle and lower panels: Active surface (DC) and number concentration (CPC) are used to derive mean mobility diameter in real time.
The two lower panels of Figure 19 apply the concept of DC/CPC derived mean diameter on a real-time basis, following the same cold-start UDC. Similarly to the previous case, lower mean particle diameters are generally calculated for the first seconds of the cycle. This confirms the indication for nucleation mode potential. A peak has also been isolated in the region of $450 \mathrm{~s}$. There is larger deviation between DC and ELPI signals which also corresponds to a decrease of particle mean diameter from $\sim 80 \mathrm{~nm}$ to $\sim 50 \mathrm{~nm}$. This is again a good indication of nucleation mode formation during the acceleration, provided by three instruments.

\section{COMPARISON WITH CHASING EXPERIMENTS}

As pointed out above, aim of the developed PFSS has not been to mimic atmospheric mixing and dilution, but to reproduce conditions which can realistically favor nucleation mode formation, should such a potential exist In order to explore this potential we performed comparative tests with the Euro $3 \mathrm{VW}$ Golf TDI which has been shown to consistently produce a distinct nucleation mode under high speed conditions in the lab (see for example Figure 18). The tests involved measurements in the lab using the PFSS and measurements chasing the same vehicle using the Ford Mobile Laboratory (FML). This is a Ford Transit van equipped with instrumentation for the measurement of gaseous and particle emissions [34].

In these tests, FML measured the size distribution of particles in the plume of the front vehicle (VW Golf) with an SMPS, keeping a distance of $\sim 14 \mathrm{~m}$ which corresponds to a RT in the atmosphere of $1 \mathrm{~s}$ at $50 \mathrm{~km} / \mathrm{h}$ and $0.4 \mathrm{~s}$ at $120 \mathrm{~km} / \mathrm{h}$. The dilution factor was calculated by comparing the $\mathrm{CO}_{2}$ emission rate measured during chasing with the emission rate in the undiluted exhaust obtained at the same speed in the emission lab. The onboard fuel consumption measurement showed a lower fuel consumption of $4 \%$ or $16 \%$ for 50 and $120 \mathrm{~km} / \mathrm{h}$, respectively during the dynamometer tests. Unfortunately, most of the laboratory runs were carried out at the corresponding lower fuel consumption and dynamometer load. For the tests reported here, actual DR ranges were in the order of $2500: 1$ at $50 \mathrm{~km} / \mathrm{h}$ and $7000: 1$ at $120 \mathrm{~km} / \mathrm{h}$ while ambient temperature was about $5^{\circ} \mathrm{C}$ and ambient air $\mathrm{RH}$ in the order of $50 \%$.

Figure 20 shows the size distributions obtained in these experiments. In the upper panel, distributions obtained at $50 \mathrm{~km} / \mathrm{h}$ are compared. Both the shape and the concentration of the distributions are remarkably similar. There is a slightly higher concentration of particles $<30 \mathrm{~nm}$ in the "chasing" condition but difference with the PFSS is too small to attempt any credible explanation. There is a more interesting comparison at $120 \mathrm{~km} / \mathrm{h}$. in this case, a nucleation mode forms both in the chasing and the laboratory experiments. In the former case, a distinct bimodal distribution is formed with two clear peaks at $12 \mathrm{~nm}$ and $64 \mathrm{~nm}$. Distributions obtained in the lab also form a nucleation mode. Depending on RT, nucleation mode peak ranges from $21 \mathrm{~nm}$ to $39 \mathrm{~nm}$. 
Moreover, when a short RT is established ( $\sim 0.5 \mathrm{~s})$, accumulation modes between the PFSS and the chasing experiment are identical. When RT increases, the accumulation mode shifts to larger sizes.
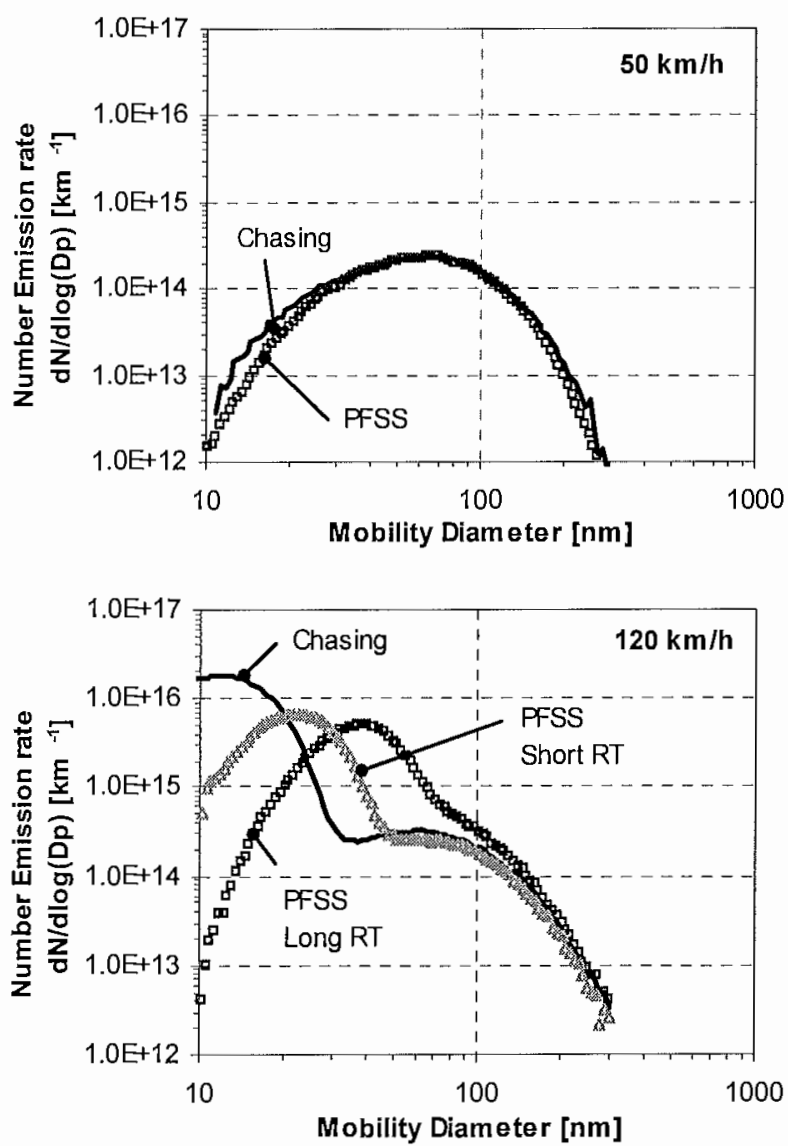

Figure 20: Comparison of particle size distributions obtained with the PFSS in the lab and with ambient diluted samples obtained chasing a VW Golf TDI Euro 3 vehicle. Upper panel obtained at $50 \mathrm{~km} / \mathrm{h}$ and lower panel at $120 \mathrm{~km} / \mathrm{h}$. At the lower panel, two different PFSS setups correspond to short RT ( $0.5 \mathrm{~s})$ and long RT $(\sim 3.5 \mathrm{~s})$.

This behavior is consistent with the differences in the sampling setup in each case. Under ambient mixing and dilution exhaust aerosol spends a short time under moderate dilution ratios while it spends almost $3 \mathrm{~s}$ at a DR of 12.5:1 at the laboratory experiments when long RT is used. This period has a direct effect on the nucleation mode development and growth. Hence, increase of the RT moves the distribution to larger sizes.

However, it should be recalled again that aim of the PFSS is not to simulate ambient sampling, which would require control of DR, DAT, RT and $\mathrm{RH}$ for each particular ambient condition and vehicle operation. The target has been to produce repeatable sampling conditions with the potential to produce nucleation mode. In this respect, the results above show clearly that nucleation mode formation potential is accurately reproduced in the laboratory obtained distributions.

\section{SUMMARY AND CONCLUSIONS}

In the framework of the PARTICULATES project, a sampling system for airborne particle characterization was developed and evaluated. The sampling system draws a constant flowrate of exhaust gas over steady state and transient tests which is diluted at a desired ratio and temperature. The sample is then analyzed with several aerosol instruments, including a gravimetric impactor, an ELPI, a diffusion charger and an SMPS/CPC. Distinction between total and solid particles is also made. Based on the evaluation of the system performance, the following conclusions can be drawn:

1. The sampling system enables a broad characterization of particle properties over transient tests in real time. These include total particle number concentration, active surface, and particle number concentration and size distribution of solid particles. Additionally, average mass-weighted size distributions can be obtained over transient tests and number based size distributions over steady state tests.

2. The primary dilutor is capable of producing a distinct nucleation mode, depending on the sampling conditions selected. Selection of 12.5:1 DR and $32^{\circ} \mathrm{C}$ of DAT has been shown to be favorable for a repeatable nucleation mode formation.

3. Control of the primary DR is critical for a PFSS operating with constant sample flow. We have identified conditions where sampling can be problematic, especially for pulsating exhaust flow. However, sampling at the tailpipe end downstream of a muffler and/or aftertreatment devices significantly reduces the $D R$ variation.

4. Determination of DR over transient tests is problematic with conventional gaseous analyzers and long sampling lines. Fuel cut-off periods make DR determination impossible. However, comparison of solid particles in the CVS and PFSS show that a constant DR can be used for the whole transient test.

5. Secondary dilution does not seem to significantly affect particle size distribution, neither to induce significant particle losses. However, secondary DR determination needs to be routinely checked depending on ejector dilutor operating history.

6. The denuder is efficient in removing small nucleation mode particles and only log-normal accumulation mode particles are sampled downstream. It also induces significant solid particle losses which can be corrected. This increases the uncertainty of the measurement.

7. There is a satisfactory repeatability in several particle parameters examined. CoVs are in the order of $10 \%$ for accumulation mode particles and $50 \%$ for nucleation mode ones. Vehicle conditioning may also influence nucleation mode behavior.

8. There is good reproducibility in measurements conducted at different labs, with CoV values ranging from below $20 \%$, over transient cycles, to up to $40 \%$, over steady state speeds, for three aerosol instruments examined. 
9. Mass collected in the gravimetric impactor agrees with the CVS PM over steady state tests. This is a good indication of the overall system performance and aspiration efficiency. Over transient tests, there is underestimation of the mass collected, as expected for a constant sample flowrate sampling system.

10. Combination of information provided by different instruments can provide the means to deduce particle properties in real-time. Additionally, crosschecking of different properties can provide an overall quality control framework for the measurement.

11. Comparison of PFSS laboratory measurements with size distributions obtained by chasing experiments demonstrated that the sampling system developed is able to accurately reproduce the accumulation mode and the potential for nucleation mode formation.

\section{ACKNOWLEDGMENTS}

This work has been conducted in the framework of the EC DG TREN "PARTICULATES" project (Contract No. 2000-RD.11091). The authors would like to thank all partners for a constructive collaboration and significant contribution in all stages of the project development. In particular we would like to recognize the contributions from Päivi Aakko of VTT Finland, Claes De Serves of AVL MTC Sweden, Laurent Forti of IFP France, Stefan Hausberger of Technical University Graz Austria, Theodor Sams of AVL Austria, Richard Stradling of Shell Global Solutions, UK and Urban Wass of Volvo Technology Sweden who organized the installation of a PFSS in their facilities for the execution of a painstaking measurement campaign. Finally, Prof. David Kittelson is greatly acknowledged for his constructive contribution in developing the sampling setup.

\section{REFERENCES}

1. Khalek, I.A.; Kittelson, D.; Brear, F. 1999. The Influence of Dilution Conditions on Diesel Exhaust Particle Size Distribution Measurements. SAE Paper 1999-01-1142.

2. Maricq, M.M.; Chase, R.E.; Xu, N. 2001. A Comparison of Tailpipe, Dilution Tunnel, and Wind Tunnel Data in Measuring Motor Vehicle PM. J. Air \& Waste Manage. Assoc., Vol. 51, pp. 1529-1537.

3. Federal Register: January 18, 2001, Volume 66, Number 12, Rules and Regulations "Control of Emissions from New and In-Use Highway Vehicles".

4. MacDonald, J.S.; Plee, S.L.; D'Arcy, J.B.; Schreck, R.M. 1980. Experimental Measurements of the Independent Effects of Dilution Ratio and Filter Temperature on Diesel Exhaust Particulate Samples. SAE Paper 800185.
5. Reichel, S.; Pischinger, F.F.; Lepperhoff, G. 1983. Influence of Particles in Diluted Diesel Engine Exhaust Gas. SAE Paper 831333.

6. Khalek, I.A.; Ulman, T.L.; Shimpi, S.A.; Jackson, C.C.; Dharmawardhana, B.; Silvis, W.M.; Kreft, N.; Harvey, R.N.; Munday, D.; Yamagishi, Y.; Graze, R.; Smitherman, J.; Adkins, J. 2002. Performance of Partial Flow Sampling Systems Relative to Full Flow CVS for Determination of Particulate Emissions under SteadyState and Transient Diesel Engine Operation. SAE Paper 2002-01-1718.

7. Durán, A.; de Lucas, A.; Carmona, M.; Ramos, M.J.; Armas, O. 2002. Accuracy of the European Standard Method to Measure the Amount of DPM Emitted to the Atmosphere. Fuel, Vol.81, pp. 2053-2060.

8. Silvis, W.M.; Marek, G.; Kreft, N.; Schindler, W. 2002. Diesel Particulate Measurement with Partial Flow Sampling Systems: A New Probe and Tunnel Design that Correlates with Full Flow Tunnels. SAE Paper 2002-010054.

9. Traver, M.L.; Tennant, C.J.; McDaniel, T.I.; McConnell, S.S.; Bailey, B.K.; Maldonado, H. 2002. Interlaboratory Cross-Check of Heavy-Duty Vehicle Chassis Dynamometers. SAE Paper 2002-01-2879.

10. Khalek, I.A.; Kittelson, D.B.; Graskow, B.R.; Wei, Q.; Brear, F. 1998. Diesel Exhaust Particle Size: Measurement Issues and Trends. SAE Paper 980525.

11. Lüders, H.; Krüger, M.; Stommel, P.; Lüers, B. 1998. The Role of Sampling Conditions in Particle Size Distribution Measurements. SAE Paper 981374.

12. Andersson, J.; Wedekind, B.; Hall, D.; Stradling, R.; Barnes, C.; Wilson, G. 2000. DETR/SMMT/CONCAWE Particle Research Program: Sampling and Measurement Experiences. SAE Paper 2000-01-2850.

13. Maricq, M.M.; Chase, R.E.; Podsiadlik, D.H.; Vogt, R. 1999. Vehicle Exhaust Particle Size Distributions: A Comparison of Tailpipe and Dilution Tunnel Measurements. SAE Paper 1999-01-1461.

14. Hall, D.; Dickens, C.J. 2000. Measurement of the Numbers of Emitted Gasoline Particles: Genuine or Artefact?. SAE Paper 2000-01-2957.

15. Vouitsis, E.; Ntziachristos, L.; Samaras, Z. 2003. Particulate Matter Mass Measurements for Low Emitting Diesel Powered Vehicles: What's Next?. Progress in Energy and Combustion Science 29 (2003) 635-672.

16. Mikkanen, P.; Moisio, M.; Keskinen, J.; Ristimäki, J.; Marjamäki, M. 2001. Sampling Method for Particle Measurements of Vehicle Exhaust. SAE Paper 2001-010219.

17. Mayer, A.; Czerwinski, J.; Matter, U.; Wyser, M.; Scheidegger; Kieser, D.; Weidhofer. 1998. VERT: Diesel Nano-Particulate Emissions: Properties and Reduction Strategies. SAE Paper 980539.

18. Ntziachristos, L.; Samaras, Z. 2000. Sampling Conditions Effects on Real-Time Particle Measurements from a Light Duty Vehicle. SAE Paper 2000-01-2049.

19. Siegmann, K.; Siegmann, H.C. 2000. Fast and Reliable "in Situ" Evaluation of Particles and their Surfaces wirh Special Reference to Diesel Exhaust. SAE Paper 2000-01-1995. 
20. Bukowiecki, N.; Kittelson, D.B.; Watts, W.F. Burtscher, H.; Weingartner, E.; Baltensperger, U. 2002 Real-time Characterization of Ultrafine and Accumulation Mode Particles in Ambient Combustion Aerosols Aerosol Science, Vol. 33, pp. 1139-1154.

21. Ntziachristos, L.; Giechaskiel, B.; Ristimäki, J.; Keskinen, J. 2003. Use of a Corona Charger for the Characterization of Automotive Exhaust Aerosol. Submitted for publication to Aerosol Science.

22. ACEA, 2002. ACEA Programme on Emissions of Fine Particles from Passenger Cars [2]. July 2002,

Brussels, Belgium, p.96.

23. Keskinen, J.; Virtanen, A.; Ristimäki, J. 2003. Real time Measurement of the Effective Density and Fractal Dimension of Diesel Exhaust Particles. 7th ETH Conference on Combustion Generated Particles. Zurich, August, 18-20, 2003.

24. Cheng, M.D.; Storey, J.M.; Wainman, Th.; Dam, Th. 2002. Impacts of Venturi Turbulent Mixing on the Size Distributions of Sodium Chloride and Dioctyl-Phthalate Aerosols. Aerosol Science, Vol. 33, pp. 491-502.

25. Dekati, 2002. Performance Evaluation of the Dekati Thermodenuder, ver. 1.3. Tampere, Finland.

26. Andresson, J.D. (2003). UK Particle Measurement

Programme Phase 2 - Heavy Duty Methodology

Development. Final Report. Ricardo DP03/21201, p. 207.

27. Hinds W.C. Aerosol Technology. Properties, Behaviour, and Measurement of Airborne Particles. Wiley-Interscience; 2nd edition, 1999.

\section{CONTACT}

Zissis Samaras, Professor

Laboratory of Applied Thermodynamics

Aristotle University

GR-54124 Thessaloniki Greece

Email: zisis@auth.gr

Web: http://lat.eng.auth.gr

\section{ADDITIONAL SOURCES}

Additional information on the sampling system characteristics and the PARTICULATES project may be found at http://vergina.eng.auth.gr/mech/lat/particulates.
28. Baron, P.A.; Willeke, K. Aerosol Measurement: Principles, Techniques, and Applications, 2nd Edition. Wiley-Interscience; 2nd edition, 2001.

29. Wang, J.; Flagan, R.C.; Seinfeld, J.H. 2002. Diffusional Losses in Particle Sampling Systems Containing Bends and Elbows. Aerosol Science, Vol. 33, pp. 843-857.

30. Kittelson, D.B.; Johnson, J. 1991. Variability in Particle Emission Measurements in the Heavy Duty Transient Test. SAE Paper 910738.

31. Stein, H.J.; Ekermo, A.I.; Treiber, P.J.H. 1989

Emissions Correlation of Heavy-Duty Transient Test Facilities. SAE Paper 892492.

32. Ahlvik, P.; Ntziachristos, L.; Keskinen, J.; Virtanen A. 1998. Real Time Measurements of Diesel Particle Size Distribution with an Electrical Low Pressure Impactor. SAE Paper 980410.

33. Ristimäki, J.; Virtanen, A.; Marjamäki, M.; Rostedt, A.; Keskinen, J. 2002. On-line Measurement of Size Distribution and Effective Density of Submicron Aerosol Particles. Aerosol Science, Vol. 33, pp. 1541-1557.

34. Vogt, R.; Scheer, V.; Casati, R.; Benter, Th. 2003.

On-road Measurement of Particle Emission in the Exhaust Plume of a Diesel Passenger Car.

Environmental Science \& Technology, Vol. 37, pp. 40704076.

\section{DEFINITIONS, ACRONYMS, ABBREVIATIONS}

CPC: Condensation Particle Counter

CVS: Constant Volume Sampling

CoV: Coefficient of Variance (standard deviation over mean value)

DAT: Dilution Air Temperature

DC: Diffusion Charger

DMA: Differential Mobility Analyzer

DR: Dilution Ratio

ELPI: Electrical Low Pressure Impactor

FID: $\quad$ Flame Ionization Detector

FML: Ford Mobile Lab

PFSS: Partial Flow Sampling System

PM: Particulate Matter

PMP: Particle Measurement Programme

RH: Relative Humidity

RT: Residence Time

SD: $\quad$ Standard Deviation

SMPS: Scanning Mobility Particle Sizer

TD: Thermodenuder

UDC: Urban Driving Cycle 